
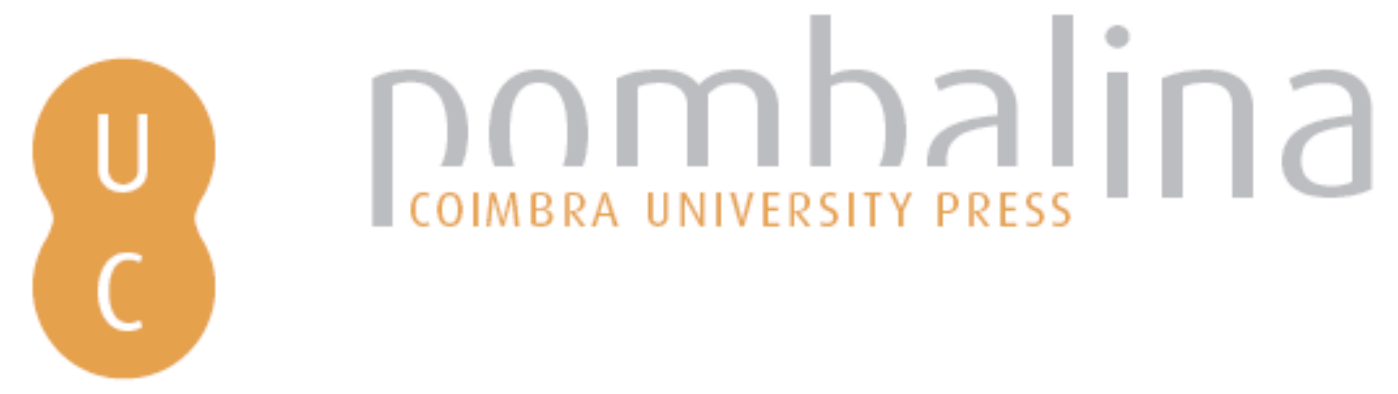

\title{
Transporte multiproduto por oleoduto e gestão de parque de tanques: 0 caso da companhia logística de combustíveis
}

\author{
Autor(es): $\quad$ Relvas, Susana; Póvoa, Ana Paula F. D. Barbosa; Matos, Henrique A. \\ Publicado por: Imprensa da Universidade de Coimbra \\ URL \\ persistente: URI:http://hdl.handle.net/10316.2/35934 \\ DOI: $\quad$ DOI:http://dx.doi.org/10.14195/978-989-26-0738-2_13 \\ Accessed : $\quad$ 26-Apr-2023 16:11:15
}

A navegação consulta e descarregamento dos títulos inseridos nas Bibliotecas Digitais UC Digitalis, UC Pombalina e UC Impactum, pressupõem a aceitação plena e sem reservas dos Termos e Condições de Uso destas Bibliotecas Digitais, disponíveis em https://digitalis.uc.pt/pt-pt/termos.

Conforme exposto nos referidos Termos e Condições de Uso, o descarregamento de títulos de acesso restrito requer uma licença válida de autorização devendo o utilizador aceder ao(s) documento(s) a partir de um endereço de IP da instituição detentora da supramencionada licença.

Ao utilizador é apenas permitido o descarregamento para uso pessoal, pelo que o emprego do(s) título(s) descarregado(s) para outro fim, designadamente comercial, carece de autorização do respetivo autor ou editor da obra.

Na medida em que todas as obras da UC Digitalis se encontram protegidas pelo Código do Direito de Autor e Direitos Conexos e demais legislação aplicável, toda a cópia, parcial ou total, deste documento, nos casos em que é legalmente admitida, deverá conter ou fazer-se acompanhar por este aviso.

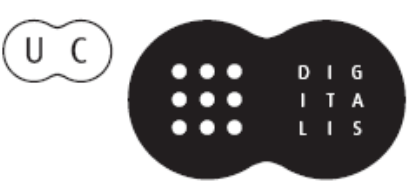




\section{INVESTIGAÇÃO OPERACIONAL EM AÇÃO \\ CASOS DE APLICAÇÃO}

RUI CARVALHO OLIVEIRA JOSÉ SOEIRO FERREIRA (EDITORES)

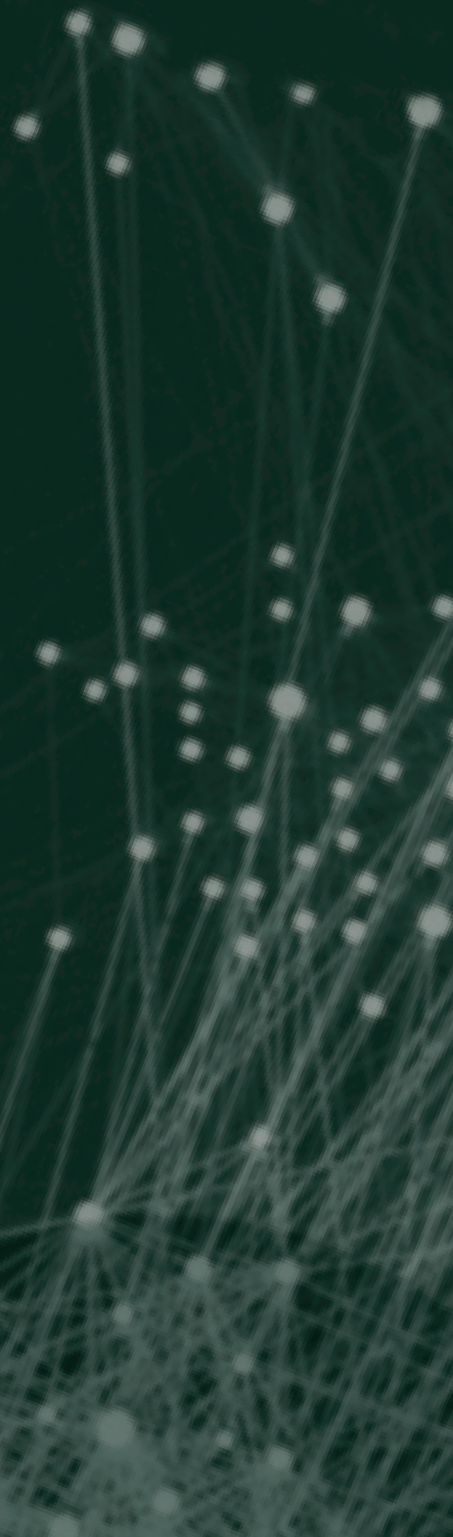




\section{CASO 13}

\section{TRANSPORTE MULTIPRODUTO POR}

Oleoduto e Gestão de Parque de

TANQUES: O CASO DA COMPANHIA LOgísticA DE COMBUSTÍveIS

Susana Relvas

CEG-IST - Centro de Estudos de Gestão do IST, Instituto Superior Técnico

Universidade de Lisboa susana.relvas@tecnico.ulisboa.pt

Ana Paula F.D. Barbosa Póvoa CEG-IST -- Centro de Estudos de Gestão do IST, Instituto Superior Técnico Universidade de Lisboa apovoa@tecnico.ulisboa.pt

Henrique A. Matos CERENA-Centro de Recursos Naturais e Ambiente, Instituto Superior Técnico Universidade de Lisboa henrimatos@tecnico.ulisboa.pt 


\section{RESUMO}

A cadeia de abastecimento do petróleo (CAP) engloba várias entidades e funções, desde a exploração e transformação de crude, até à distribuição final. A competitividade no setor e os custos crescentes têm levado os seus decisores a procurar novas estratégias e melhorias nos processos a vários níveis, nomeadamente na vertente logística desta cadeia.

É exemplo de atividade logística na CAP a Companhia Logística de Combustíveis (CLC), que é responsável pela operação do oleoduto multiproduto entre a Refinaria de Sines e o Parque de Tanques em Aveiras de Cima bem como pela gestão de inventário dos derivados de petróleo que chegam ao seu centro de distribuição, em Portugal. O planeamento do transporte de produtos pelo oleoduto requer a integração da competição entre produtos no escalonamento do transporte, com o fornecimento do mercado e a produção de derivados a montante.

Neste sentido, surgiu em 2005 a colaboração científico-tecnológica entre a CLC e o Instituto Superior Técnico (IST), com o objetivo de sistematizar e otimizar o planeamento de operações a cargo desta empresa. Este objetivo passa pelo estudo do escalonamento do transporte de produtos através de oleodutos multiproduto com integração da gestão de inventário no Parque de Tanques. A metodologia adotada consiste no desenvolvimento de modelos matemáticos de programação linear inteira mista (MILP - Mixed Integer Linear Programming) suportados por heurísticas desenhadas para reduzir a complexidade do espaço de soluções e obter soluções em períodos de tempo útil. O objetivo final desta investigação é o desenvolvimento de um Sistema de Apoio à Decisão para o planeamento das operações neste sistema logístico, cujo processo de validação, desenvolvimento e atualização decorre atualmente junto da CLC.

\section{PALAVRAS-CHAVE}

Oleoduto multiproduto, Gestão de inventário, Escalonamento, Reescalonamento, Programação matemática, Tempo e volume contínuos 


\section{Introdução}

A Cadeia de Abastecimento do Petróleo (CAP) apresenta um impacto elevado na economia mundial. Desde os primeiros anos em que o petróleo começou a ser explorado, que tem sido usado como combustível fóssil e como matéria-prima para a produção de produtos de interesse nas diferentes fileiras industriais de forma a satisfazer as mais diversas necessidades. Inicialmente a investigação centrou-se essencialmente no desenvolvimento de novos processos industriais, seguindo-se a automação e controlo de processos e, mais recentemente, o desenvolvimento de ferramentas de apoio à decisão na procura de uma gestão otimizada dos processos produtivos nos diferentes níveis da cadeia com o objetivo de melhorar as margens de lucro globais (Shah, Li e Ierapetritou, 2011).

Nesta última vertente, um dos níveis críticos da cadeia é o transporte e distribuição de produtos petrolíferos. Uma das necessidades identificadas como importantes prende-se com o desenvolvimento de metodologias de otimização que permitam a definição de estratégias sustentadas de planeamento do transporte e distribuição. Nesta área, os oleodutos aparecem como um equipamento essencial no transporte de volumes elevados, com custos relativamente baixos, ao longo de variadas distâncias e configurações em rede, garantido uma operação segura e fiável (Trench, 2001).

É neste contexto que se enquadra a história e operação da Companhia Logística de Combustíveis (CLC), que opera em Portugal o oleoduto multiproduto que interliga a Refinaria de Sines ao Parque de Tanques da CLC situado em Aveiras de Cima (Figura 1) e que abastece a zona centro do território continental do país.

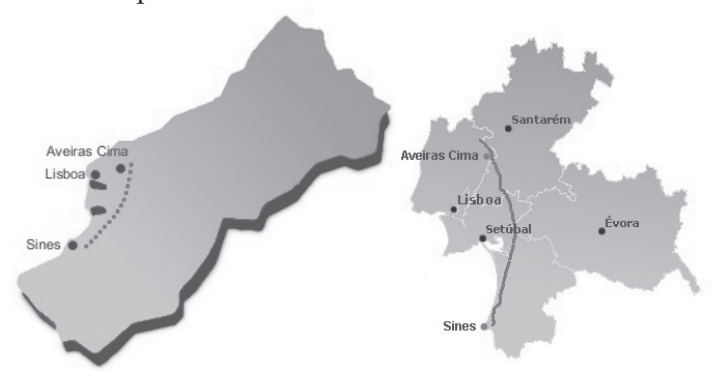

Figura 1: Oleoduto da CLC 
Com o aumento de complexidade da operação e dinamismo do mercado, a CLC assumiu a necessidade de sistematizar o planeamento da sua operação. Surge então a oportunidade de colaboração com o Instituto Superior Técnico (IST), por intermédio de uma equipa de investigadores do Grupo de Operações e Logística do Centro de Estudos de Gestão (CEG-IST) e do Grupo de Integração e Otimização de Processos do Centro de Processos Químicos (CPQ).

O objetivo delineado para esta colaboração é o desenvolvimento de um sistema de apoio à decisão que permita desenvolver o planeamento mensal das operações de transporte de produtos por oleoduto e a associada gestão de inventário no parque de tanques, ambos geridos pela CLC.

Este artigo irá detalhar um estudo de caso que explora o escalonamento da operação do oleoduto operado pela CLC. O capítulo 2 é reservado à definição do problema em estudo, onde será feito um enquadramento real (secção 2.1) e científico (secção 2.2) do problema. A secção 2.3 consiste numa definição do problema em estudo e, posteriormente, a secção 2.4 apresenta os principais pressupostos e considerações que levam à construção dos modelos de otimização. O método de solução é então explorado no capítulo 3, começando a secção 3.1 por apresentar o enquadramento geral e cronológico do processo de desenvolvimento do método proposto. A secção 3.2 apresenta os pressupostos base à construção dos modelos MILP. As secções 3.3 e 3.4 resumem várias estratégias adotadas na representação do problema e redução do espaço de solução do mesmo. O capítulo 4 é inteiramente dedicado à apresentação sucinta da formulação do modelo base do método de solução (modelo I). O capítulo 5 apresenta vários cenários de validação e resultados obtidos pela implementação do método desenvolvido. O capítulo 6 está reservado para a etapa de transferência de tecnologia, onde foi desenvolvida uma interface com o utilizador (secção 6.1) que foi caracterizada e avaliada (secções 6.2 e 6.3). Por fim, serão apontadas as principais conclusões e direções para trabalho futuro no capítulo 7. 


\section{Definição do Caso de Estudo}

Nesta secção, com base no enquadramento real do problema e na literatura da área, será definido o problema a estudar. Esta definição passará por uma primeira fase em que a definição é genérica e numa segunda fase onde serão feitas algumas considerações que permitem moldar o problema real ao problema definido.

\subsection{Enquadramento do Problema Real}

A CLC é a principal empresa Portuguesa de distribuição logística a operar em Portugal. Garante a operação do oleoduto multiproduto, que interliga a refinaria localizada em Sines (sul de Portugal) com o seu parque de tanques localizado em Aveiras de Cima. Este oleoduto tem um total de $147 \mathrm{~km}$ e possui $18.000 \mathrm{~m}^{3}$ de capacidade.

A origem da CLC remonta à década de 90 do século XX, onde por motivos de realização da EXPO 98 na zona oriental de Lisboa, se decidiu desmantelar a Refinaria de Cabo Ruivo. Por um lado, a produção aí realizada foi deslocalizada para as restantes duas Refinarias da Petrogal (hoje Galp). No que respeita à componente logística de distribuição de produtos foi tomada a decisão sobre uma alternativa que mantivesse o abastecimento da zona centro de Portugal. Foi então decidido constituir a CLC, localizada em Aveiras de Cima, onde um Parque de Tanques seria abastecido por oleoduto a partir da Refinaria de Sines. Além de abastecer a mesma zona que a anterior alternativa, permitiu retirar o tráfego diário de cerca de 500 camiões cisterna com combustíveis a circular dentro da cidade de Lisboa.

O oleoduto foi construído entre 1996 e 1997 e a operação da CLC teve início em Abril desse ano (CLC, 2011).

As instalações da CLC cobrem uma área de cerca de 60 ha, incluindo, entre outros, tanques e esferas de armazenagem, num total atual de 14 esferas e 22 tanques, e a estação de receção do oleoduto.

O oleoduto transporta atualmente sete produtos (P1-P7), sendo cinco deles produtos brancos e os restantes dois gases liquefeitos. Dado que o transporte é feito sem elementos separadores entre batches (um batch ou lote consiste no volume de um único produto bombeado e delimitado por dois batches de 
outros produtos um a montante e outro a jusante) de sucessivos de produtos, é conhecida a matriz de sequências possíveis entre pares de produtos que garantem a manutenção da qualidade dos mesmos.

Os produtos são fornecidos exclusivamente pela Galp, enquanto a CLC possui vários clientes. Sendo que o consumo da CLC representa cerca de $40 \%$ da expedição da refinaria de Sines, o planeamento de operações é feito numa base mensal, que pode ser integrada no plano de produção da Refinaria da Galp em Sines. Para este efeito, a CLC recebe a meio de cada mês uma previsão mensal (com quantidades numa base diária) dos consumos previstos pelos seus clientes. Com base nesta previsão, os chefes de turno da sala de controlo elaboram um plano de transporte e gestão de tanques para o mês de calendário seguinte, que validam junto da Galp.

O plano de transporte deve garantir as sequências possíveis de produtos dentro do oleoduto e garantir ainda que são respeitados os limites mínimos e máximos de caudal de bombagem e de capacidade de armazenagem no parque de tanques. No que respeita ao parque de tanques, há que garantir que em todo o momento existe produto para satisfazer os clientes. Este exercício implica que a gestão de inventário no Parque de Tanques da CLC seja coordenada com o plano de transporte de produtos pelo oleoduto. Assim, em cada mês, os chefes de turno elaboram, com base na sua experiência, dois documentos baseados em folha de cálculo e que denominam por Ordem de Bombagem (plano de transporte de produtos através do oleoduto) e Movimentação de Tanques (gestão de inventário no parque de tanques).

A primeira versão de cada um destes documentos é feita usualmente num turno da noite, onde existe menor atividade no parque, com base nas restrições físicas do sistema e também em algumas restrições operacionais. Por exemplo, caso tenham de ocorrer paragens, tenta-se que estas ocorram com o mínimo de produtos dentro do oleoduto. Por fim, tenta-se que um batch de um determinado produto encha por completo um ou mais tanques, a fim de manter a rastreabilidade dos produtos e também minimizar o efeito de alguma fração de interface que seja diluída nesse batch.

A CLC identificou que este método não é sistemático e é unicamente baseado na experiência dos seus chefes de turno. Não são exploradas sinergias 
no planeamento que um método de otimização pode permitir. Além disso, com a evolução da sua operação e do próprio mercado, que atualmente é muito dinâmico e competitivo, mais restrições e direções operacionais surgem. Assim, o método original de planeamento da CLC torna-se pouco flexível e apenas permite enumerar uma solução possível.

\subsection{Enquadramento do Problema em Estudo}

A literatura existente na área da gestão da cadeia de abastecimento do petróleo foca-se, desde os primeiros anos, nas operações de refinação, uma vez que são a atividade principal desta cadeia. No entanto, nos últimos anos têm surgido trabalhos focados quer na cadeia como um todo (Más e Pinto, 2004), permitindo a integração de operações, quer na distribuição (aqui desde a distribuição rodoviária até ao uso de oleodutos), onde várias vantagens competitivas podem ser atingidas. Na área de transporte e distribuição, os oleodutos aparecem como um equipamento essencial para o transporte de volumes elevados, com custos relativamente baixos, ao longo de distâncias variadas e configurações em rede, garantido uma operação segura e fiável. Na Europa a 27, a densidade de oleodutos era, em 2008, de 8 km/1000 km², correspondendo a mais de $30000 \mathrm{~km}$ de tubagem, representando um transporte de 135637 milhões de km de crude e seus derivados (Eurostat Pocket Book, 2008; Noreland, 2008). Apesar de o planeamento de operações neste tipo de equipamentos ser complexo, a falta de soluções comerciais leva a que a maioria das empresas se mantenha a utilizar ferramentas simples baseadas em folha de cálculo, experiência dos programadores e iterações sucessivas. Neste sentido, existe uma enorme oportunidade nesta área para a comunidade científica.

As metodologias de planeamento para a operação de oleodutos têm na programação matemática o método com maiores progressos (de entre um conjunto abrangendo também a simulação e heurísticas - Sasikumar et al. 1997 - de índole mais avançado), sendo o trabalho pioneiro de Shah datado de 1996. Os oleodutos multiproduto têm motivado duas linhas de modelos de representação baseados em programação matemática, em que o tempo é 
modelado de forma discreta (Magatão et al., 2004, Rejowski e Pinto, 2004) ou contínua (Cafaro e Cerdá, 2004, 2008 e Rejowski e Pinto, 2008).

Mais recentemente os métodos de solução expandiram-se para vários tipos de topologias de oleodutos, desde o oleoduto simples (uma entrada e saída, Relvas et al., 2006), até às redes de oleodutos (Boschetto et al., 2010). Outros trabalhos têm integrado a operação do oleoduto com operações a montante ou jusante (Relvas et al., 2006 e 2007; Relvas, 2008; Relvas, Barbosa-Póvoa e Matos, 2009).

A revisão bibliográfica na área permite concluir que na maioria dos casos têm sido usados modelos MILP para resolução destes problemas, recorrendo a algoritmos comerciais com elevado potencial de resolução na procura de soluções. Os modelos MILP permitem combinar a programação linear contínua com programação inteira, onde diversos tipos de decisões podem ser modelados. Em alguns casos, nomeadamente em aplicações reais, recorre-se adicionalmente e de forma integrada a heurísticas que permitam reduzir o espaço de soluções e permitam encontrar soluções em tempo real, como no caso do trabalho de Boschetto et al. (2010).

\subsection{Definição do Problema em Estudo}

O problema em estudo considera o transporte de produtos derivados do petróleo, desde uma refinaria até um parque de tanques, através de um oleoduto multiproduto (Figura 2). No oleoduto os produtos são bombeados sem que exista uma separação física entre produtos, limitando o mapa de sequências possíveis de modo a garantir a qualidade do produto final. O centro de distribuição é responsável por satisfazer as necessidades do mercado local, que se traduz por uma carteira específica de clientes com procura conhecida e definida sobre uma escala temporal diária. Cada produto, quando alcança o final do oleoduto, é armazenado em um ou mais tanques os quais armazenam sempre esse mesmo produto. Cada tanque que recebe produto deve repousar durante um determinado período de tempo, após o qual pode fornecer os clientes até ao estado vazio. O ciclo repete-se ao longo do tempo. 


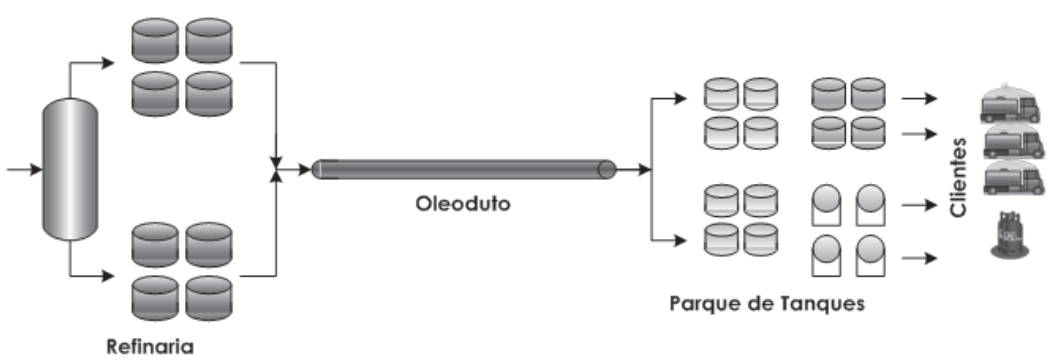

Figura 2 - Esquematização do Sistema em Estudo

O problema pode então ser definido na seguinte estrutura:

Dado: i) o número de produtos a bombear; ii) a matriz de sequências possíveis entre pares de produtos consecutivos; iii) o volume do oleoduto; iv) os caudais mínimo e máximo de bombagem; v) o número máximo de batches a transportar; vi) a extensão do horizonte temporal; vii) o serviço de tanque (alocação de tanques a produtos); viii) os inventários iniciais de cada produto em cada tanque; ix) a capacidade máxima de armazenagem por tanque; $\mathrm{x}$ ) os produtos e quantidades que se encontram inicialmente no oleoduto; xi) as previsões de saídas de produtos para clientes; e xii) as condições temporais para a localização de possíveis paragens pré-estabelecidas do oleoduto;

Determinar: 1) o escalonamento da bombagem de produtos no oleoduto, nomeadamente a sequência de produtos e o número de batches a bombear, volumes e caudais de bombagem por batch, início e final da bombagem de cada batch para o oleoduto, a localização e duração das paragens préestabelecidas do oleoduto; e 2) a gestão de inventário no parque de tanques, incluindo o perfil de inventário por produto (e por tanque) e a monitorização das chegadas de produtos, aprovação e repouso de batches e expedição de produtos para clientes;

A fim de otimizar um objetivo representado por uma função de indicadores de operação.

\subsection{Considerações sobre o Problema em Estudo}

De modo a propor um método de resolução do problema descrito que se adeque não só ao problema de investigação em estudo, tal como definido na 
secção 2.3, mas também ao problema real, devem ser analisadas algumas questões operacionais que suportem a metodologia a desenvolver.

No caso real da CLC, o seu parque de tanques é abastecido exclusivamente a partir da refinaria de Sines, pelo que é relevante o volume requerido pela CLC para o planeamento da produção. O planeamento da produção é feito numa base mensal, o que implica que o planeamento da operação de transporte pelo oleoduto seja feito também na mesma base. Face à literatura da área, esta questão aparece como um desafio, pois usualmente os horizontes típicos das soluções propostas até à data de início da colaboração (2005) nunca ultrapassaram 1 semana. Além deste facto, existe uma condicionante do próprio problema genérico que sugere a utilização de horizontes temporais mais extensos, apesar do planeamento ser ao nível operacional. Neste caso, o transporte sequencial de produtos no oleoduto gera um diferencial de tempo considerável desde que o produto começa a ser bombeado até que está disponível para os clientes finais. Como tal, para que as necessidades do parque de tanques se façam sentir no planeamento do transporte de produtos, o horizonte de planeamento deverá ser, no mínimo, o tempo requerido para um batch de um produto percorrer todo este processo. No caso da CLC, em média este tempo ronda as $75 \mathrm{~h}$, com casos em que as $100 \mathrm{~h}$ poderão ser atingidas. Considerando que são bombeados 7 produtos na operação da CLC e que o processo é sequencial (existe sobreposição dos períodos requeridos por produto), para repor pelo menos 1 batch de cada produto é requerida em média uma semana de operação. Assim sendo, um horizonte temporal de um mês permite bombear vários batches do mesmo produto e repor o consumo efetuado.

Por outro lado, considerando que i) a refinaria produz e armazena quantidades superiores ao requerido pela CLC, ii) o oleoduto bombeia apenas um produto de cada vez e iii) existe continuidade da produção ao longo do período de planeamento, então pode assumir-se que não existe limite de quantidade de produto para bombear à entrada do oleoduto.

Outra dificuldade no problema a abordar é a dimensão do parque de tanques da CLC. À data de início da colaboração, existiam 32 tanques (passando a 36 no ano de 2007), que se encontram divididos entre os vários 
produtos. Numa abordagem inicial considera-se que cada produto é armazenado num tanque único, agregando a capacidade real de vários tanques num só tanque. Com esta abordagem pretende-se reduzir a complexidade da representação e resolução do problema, estabelecendo um compromisso com a decisão de adotar um horizonte temporal de 1 mês. Esta simplificação implica que no volume de produto determinado pelo modelo haja produto disponível para fornecer clientes e produto que ainda está em fase de repouso, o que irá requerer o controlo de dois níveis diferentes de inventário.

No que respeita à representação temporal do problema, existem duas perspetivas. A perspetiva do cliente, que abastece produtos numa base diária e que disponibiliza com antecedência a sua previsão de consumo diária. A outra perspetiva é a do transporte de produtos no oleoduto, que se caracteriza por ser uma operação contínua. Assim sendo, será necessário lidar com esta dualidade temporal do problema.

Considerando estas questões, o primeiro foco do desenvolvimento da metodologia centra-se na operação do oleoduto, deixando para uma segunda fase a operação detalhada de gestão de inventário.

\section{Proposta de Método de Solução}

Com base na revisão da literatura e considerando a data do início da colaboração, a larga maioria das abordagens propostas ao problema em estudo consideram a utilização de modelos de otimização usando modelos do tipo MILP e usando para resolução algoritmos exatos comerciais validados pela comunidade cientifica, como o caso do CPLEX (comercializado à data pela ILOG, atualmente pela IBM). Como tal, optou-se por adotar a mesma abordagem, de modo a tirar partido do conhecimento existente. No que respeita à linguagem de modelação do problema, optou-se por adotar a linguagem de alto nível usada no software GAMS (General Algebraic Modeling System), uma vez que esta era já conhecida e dominada pela equipa do IST.

Todas estas opções foram sempre validadas junto da CLC, tendo sido discutidas as suas vantagens e desvantagens a nível operacional e a nível financeiro. 


\subsection{Enquadramento Geral e Cronológico do Método de Solução}

O método de solução proposto iniciou-se com o desenvolvimento de um conjunto de modelos matemáticos MILP que representassem o problema em estudo. A estrutura do sistema desenvolvido apresenta-se na Figura 3. Primeiramente, foi desenvolvido o Modelo I (Relvas et al. 2006, Relvas 2008), tal como denominado na Figura 3. Este modelo representa o sistema em estudo (oleoduto multiproduto e parque de tanques), onde a armazenagem é tratada de forma agregada. Os resultados da implementação deste modelo usando dados reais da CLC (Inputs) para horizontes temporais de 1 mês não permitiram obter nenhuma solução após mais de 24 h de computação. Estes resultados iniciais permitiram identificar dificuldades e concluir pela necessidade de melhorar a formulação e simplificar o processo de pesquisa de soluções. É neste sentido que surge a heurística de inicialização, desenvolvida com base no problema em estudo e validada com o caso real (Relvas, BarbosaPóvoa e Matos 2009). Os resultados obtidos da implementação da heurística permitiram obter soluções com gaps relativos inferiores a $2 \%$ em tempos de computação entre 2 e 48 min, num conjunto de testes que incluíram 6 meses distintos. Por gap relativo entenda-se o rácio (em valores absolutos) entre a diferença entre a solução atual e o melhor limite inferior (no caso de minimização) e a solução atual.

O escalonamento reativo surgiu em seguida de modo a poder responder a situações não previstas aquando do momento do planeamento inicial, permitindo assim que sejam acomodados novos dados e situações que alterem o modelo inicial.

Por fim, desenvolveu-se o Modelo II, cuja diferença para o Modelo I reside apenas na forma de representação do inventário no parque de tanques.

Nas secções seguintes serão descritas com mais detalhe as várias componentes do método proposto.

Por questões de limitação da extensão deste artigo, apenas será apresentada a formulação do Modelo I no capítulo 4, sendo que o Modelo II, a Heurística de Inicialização e o Escalonamento Reativo podem ser consultados em publicações dos autores (Relvas et al. 2006, 2007, Relvas 2008, Relvas et al. 2009) e serão brevemente discutidos nas secções deste capítulo. 


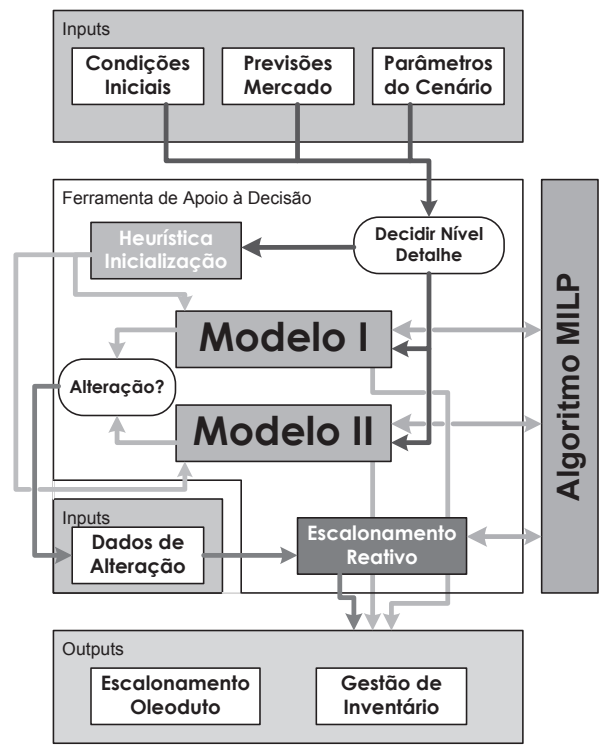

Figura 3 - Arquitectura da Metodologia desenvolvida

\subsection{Pressupostos dos Modelos de Programação Linear Inteira Mista}

Os trabalhos anteriormente publicados por Relvas et al. (2006) e Relvas (2008) descrevem o modelo MILP de representação agregada de tanques (Modelo I), tendo sido aplicado a problemas de curto e médio prazo. O modelo de representação desagregada (Modelo II) foi construído como uma alternativa em que a diferença reside na representação dos tanques. Os principais pressupostos a ter em conta na conceção dos modelos focam-se nas seguintes questões essenciais:

(1) Representação temporal e volumétrica;

(2) Representação da procura;

(3) Representação de tanques;

(4) Tempo de repouso mínimo.

- Representação temporal e volumétrica

A escala de tempo utilizada considera uma estratégia do tipo contínuo, utilizando instantes temporais nos quais se finaliza a bombagem de cada batch para o oleoduto. A formulação matemática recorre a variáveis sequenciais para 
definir a escala contínua de tempo, baseada nestes eventos. Analogamente, sabendo o volume de cada batch, através de um balanço volumétrico é calculado o volume descarregado pelo oleoduto e a evolução dos produtos ainda no interior do mesmo. Todas as restantes ocorrências no sistema (nomeadamente descarga de produtos ou atualização de perfis de inventário) são atualizadas nesta escala temporal.

- $\quad$ Representação da procura

A procura é fornecida numa base mensal ou semanal e será apresentada em intervalos discretos numa base diária. No modelo, esta informação discreta é traduzida em informação contínua por intermédio de um operador temporal que faz a correspondência entre as escalas temporais.

- $\quad$ Representação de tanques

A gestão de inventário é o fator diferenciador entre o Modelo I e o Modelo II (ver Figura 3). No caso do Modelo I, cada produto é armazenado num tanque virtual que possuiu uma capacidade igual à capacidade agregada dos tanques reais. No entanto esta agregação requer a gestão do nível de inventário global, que tem de respeitar a capacidade disponível, e o nível de inventário disponível para clientes. Este último é constituído por todo o volume de um produto armazenado no parque de tanques que já cumpriu o tempo de repouso mínimo e que deve ser o suficiente para satisfazer a procura atual daquele produto. Assim, cada batch recebido pelo oleoduto é atualizado nos dois perfis de inventário em momentos temporais diferentes e que diferem, pelo menos, no tempo mínimo de repouso (Figura 4, onde a cinzento-escuro se representa um novo batch que permanece em repouso e não disponível para clientes até cumprir o repouso mas que deve ser contabilizado para aferir se há capacidade livre ou não no tanque agregado). Note-se que o tempo de repouso depende do produto e dado a escala temporal ser contínua, o repouso de um batch pode decorrer de um a vários períodos de tempo. 


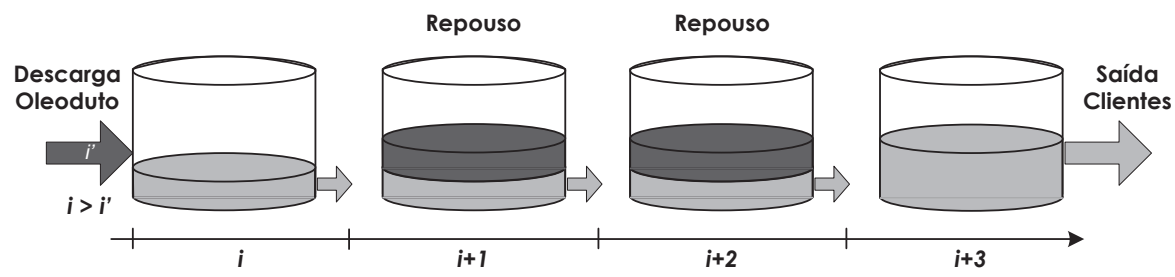

Figura 4 - Ciclo operacional de um tanque agregado (Modelo I)

O Modelo II, por sua vez, adota uma representação desagregada de tanques. Para esta formulação são definidos quatro estados de operação por tanque: E1) cheio e em repouso, E2) a disponibilizar produto para clientes, E3) vazio e E4) a receber produto do oleoduto, tal como descrito na Figura 5. Este ciclo é repetido continuamente quantas vezes necessárias no horizonte temporal. De notar que nos estados dinâmicos (E2 e E4) duas situações podem acontecer num dado intervalo de tempo: i) o tanque fornece/recebe produto e altera a sua ocupação de capacidade ou ii) o tanque está num estado em espera ou estático, mas sem ter atingido o estado cheio ou vazio. Os estados estáticos (E1 e E3) são atingidos quando o nível de inventário ultrapassa determinados níveis pré-definidos da capacidade.

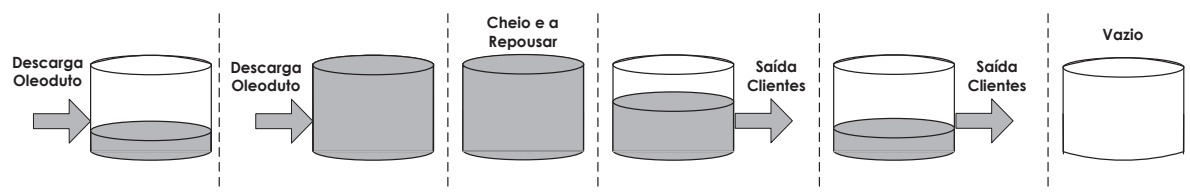

Figura 5 - Ciclo operacional de um tanque de repouso (Modelo II)

O desenvolvimento dos dois modelos reside na sua aplicabilidade. O Modelo I é aconselhável para horizontes temporais de curto a médio prazo (uma semana a um mês) e permite obter resultados que alimentem um plano de produção ao nível da refinaria. Por outro lado, o Modelo II tem caráter mais operacional, utilizando horizontes temporais curtos (semana) e fornecendo esquemas de rotação de tanques nas atividades de receção e expedição de produtos. 
- $\quad$ Tempo de repouso mínimo

O tempo mínimo de repouso considera duas situações que devem ser verificadas aquando da descarga de um novo batch para o parque de tanques: tarefas de aprovação do lote e repouso do lote, por questões standard de qualidade. Estes tempos usualmente variam com o tipo de produto. A representação do tempo de repouso é essencial num modelo matemático deste tipo, pois esta tarefa limita consideravelmente a disponibilidade de produtos no parque de tanques.

A representação do tempo de repouso varia entre os dois modelos. No caso de os tanques serem representados de forma agregada, existe a necessidade de monitorizar dois níveis de inventário e a sua viabilidade: o inventário total e o inventário disponível para clientes. Conceptualmente o inventário total permite garantir que um novo batch pode ser armazenado no parque de tanques e o inventário disponível para clientes apenas considera o volume do produto que já efetuou repouso e que está apto a ser comercializado. No que respeita a uma representação desagregada de tanques, o tempo de repouso é representado de uma forma semelhante à realidade: o tanque recetor de um novo batch entra em período de repouso até estar completo o tempo mínimo

\subsection{Método de Simplificação da Solução - Heurística de Inicialização}

Os primeiros testes ao Modelo I permitiram verificar que a definição da sequência de produtos a bombear tem elevado impacto na performance computacional. Tal facto deve-se à utilização de variáveis sequenciais que são determinadas com base na definição da sequência de produtos, que terão impacto na escala contínua de tempo (usando a duração da bombagem de cada batch em sequência) e na escala volumétrica (através do volume de cada batch bombeado). Adicionalmente, estas questões entram em conflito com aplicações de carácter real, em que é requerida uma boa solução num curto período de tempo (máximo 2 horas).

Esta situação motivou o desenvolvimento de uma heurística de sequenciação a ser utilizada antes da utilização do modelo matemático. Esta heurística analisa os dados operacionais do cenário, nomeadamente inventários iniciais e procura de produtos, bem como as restrições operacionais do período 
temporal de modo a estabelecer direções de operação. A análise destes dados permite identificar prioridades na bombagem e limites ao número de batches a bombear. As prioridades mais elevadas de produtos a bombear são determinadas considerando que o oleoduto permanece parado (ausência de novos batches) e verificando qual o produto que entra primeiro em rutura de stock. No que respeita ao número de batches a bombear, o critério consiste em considerar que se pretende repor todo o volume que é consumido por clientes durante o horizonte temporal. Considera-se ainda como dados o tempo previamente conhecido como disponível para operar e os limites de caudal de bombagem. A heurística pode ser utilizada com dois fins: geração de várias sequências fixas a utilizar no modelo para posterior comparação de resultados ou apenas inicialização da sequência e fornecimento de dados relativos aos números mínimos e máximos de batches a bombear.

A aplicação desta heurística mostrou-se essencial para diminuir a complexidade do método de resolução do problema em estudo, melhorando significativamente os tempos de computação. Verificou-se ainda que a hipótese mais viável é a geração de um conjunto de sequências fixas, direcionadas para o cenário em questão. Mais informação sobre a heurística de inicialização pode ser consultada em Relvas (2008), Relvas et al. (2009).

\subsection{Escalonamento Reativo}

Num ambiente industrial real, sujeito aos efeitos dinâmicos da cadeia de abastecimento, de mercado e operacionais, ocorrem frequentemente situações imprevistas face ao planeado. A CLC não é exceção, até porque para um período de planeamento com duração de um mês, existe uma elevada probabilidade de ocorrência de situações imprevistas ou de instabilidade dos dados usados no planeamento. Assim sendo, um dos requisitos necessários para solucionar o problema real foi o desenvolvimento de uma metodologia que permitisse refazer o planeamento com base em situações não previstas inicialmente. Para tal usou-se o escalonamento reativo, ou seja, face a uma alteração, o plano atual seria alterado para um novo plano. De modo a tornar este método viável no caso real da CLC e do contexto onde se insere, é necessário que a alteração a fazer ao planeamento seja a mínima possível, 
minimizando o impacto no sistema e na fronteira que interage com o mesmo. Para o sistema em estudo foram analisadas as situações imprevistas que ocorrem com maior frequência. A Tabela 1 apresenta a classificação adotada e a descrição como as suas causas mais comuns.

De modo a utilizar os modelos MILP desenvolvidos para o escalonamento reativo, modelaram-se matematicamente as várias potenciais ocorrências imprevistas correspondentes às situações descritas na Tabela 1.

Em seguida, foi estruturado um algoritmo de reescalonamento em que os dados operacionais relativos à situação imprevista são introduzidos, bem como os dados temporais relativos à mesma, sendo ainda fornecido o planeamento em vigor (isto porque, em situações reais, o planeamento anterior poderá já conter alterações efetuadas pelos operadores). É necessário definir o instante em que a situação é identificada e o instante em que a situação terá efeito no planeamento. O instante em que a situação é identificada será tomado pelo modelo como o instante presente. A informação proveniente do escalonamento anterior associada a instantes temporais anteriores ao instante atual é tomada como fixa (já passada). O instante ao qual a situação tem efeito será o instante a partir do qual os novos dados terão efeito no planeamento futuro.

A função objetivo além de ser função de um conjunto de indicadores de operação, terá termos de penalização cuja função é garantir desvios mínimos nas variáveis de decisão selecionadas. Deste modo garante-se que o novo planeamento considera as situações imprevistas, alterando o mínimo possível o planeamento em vigor, de modo a garantir que quer na origem quer no destino as condições de operacionalidade são mantidas.

O escalonamento reativo foi aplicado com sucesso a vários exemplos. No que respeita à aceitação por parte da CLC, esta foi extremamente positiva pois a revisão de um planeamento tem sido, segundo o seu método manual, a tarefa mais complicada de resolver. Para mais informação sobre o escalonamento reativo devem ser consultadas as publicações dos autores (Relvas et al. 2007, Relvas 2008). 
Tabela 1 - Situações imprevistas no planeamento da CLC

\begin{tabular}{|l|l|l|}
\hline & \multicolumn{1}{|c|}{ Situação } & \multicolumn{1}{c|}{ Descrição } \\
\hline S1 & $\begin{array}{l}\text { Variação da previsão da } \\
\text { procura }\end{array}$ & $\begin{array}{l}\text { Revisões periódicas ao longo do horizonte } \\
\text { temporal }\end{array}$ \\
\hline S2 & $\begin{array}{l}\text { Alteração à sequência de } \\
\text { produtos }\end{array}$ & $\begin{array}{l}\text { Essencialmente devido a alterações operatórias } \\
\text { não planeadas ou indicações provenientes de } \\
\text { outros níveis organizacionais }\end{array}$ \\
\hline S3 & $\begin{array}{l}\text { Paragem do oleoduto } \\
\text { imprevista }\end{array}$ & $\begin{array}{l}\text { Usualmente devido a rutura de stock na origem } \\
\text { ou razões operacionais (avaria nas bombas, } \\
\text { entre outras) }\end{array}$ \\
\hline S4 & $\begin{array}{l}\text { Alteração a volumes de } \\
\text { batches }\end{array}$ & Usualmente devido a rutura de stock na origem \\
\hline S5 & Ajustes de caudal & $\begin{array}{l}\text { Usualmente devido a questões operacionais } \\
\text { relativas à bombagem de produtos ou para } \\
\text { satisfazer pedidos imprevistos de clientes }\end{array}$ \\
\hline S6 & $\begin{array}{l}\text { Variação na capacidade } \\
\text { de armazenagem }\end{array}$ & $\begin{array}{l}\text { Poderá ocorrer em situações de manutenção do } \\
\text { tanque }\end{array}$ \\
\hline
\end{tabular}

\section{Formulação Matemática do Modelo I}

Neste capítulo apresenta-se sucintamente a formulação matemática do Modelo I, que representa a operação do oleoduto e a gestão de inventário de forma agregada.

\subsection{Nomenclatura}

- Índices/Conjuntos

$$
\begin{array}{ll}
i \in I & =\text { Batches } \\
p \in P & =\text { Produtos } \\
l t \in L T & =\text { Volumes discretos de batches } \\
k \in K & =\text { Dias } \\
I^{\text {new }} \subset I & =\text { Batches cuja bombagem ocorre durante o horizonte } \\
T^{\text {stop }} \in T & =\text { temporal } \\
T^{\text {start }} \in T & =\text { Instante de paragem do oleoduto }(\mathrm{h}) \\
\cdot \quad \text { Parâmetros } & \\
h_{\max } & =\text { Horizonte Temporal (h) } \\
v b_{\min } & =\text { Caudal Mínimo (uv/h) })^{1} \\
v b_{\max } & =\text { Caudal máximo (uv/h) }
\end{array}
$$$$
T^{\text {stop }} \in T=\text { Instante de paragem do oleoduto }(\mathrm{h})
$$

\footnotetext{
${ }^{1}$ uv - unidades volumétricas
} 


\begin{tabular}{|c|c|c|}
\hline$D_{\max }$ & $=$ & $\begin{array}{l}\text { Limite superior de volume a descarregar do oleoduto num } \\
\text { período de tempo (uv) }\end{array}$ \\
\hline$D_{\min }$ & $=$ & $\begin{array}{l}\text { Limite superior de volume a descarregar do oleoduto num } \\
\text { período de tempo (uv) }\end{array}$ \\
\hline$\sigma$ & $=$ & Coordenada volumétrica do ponto final do oleoduto (uv) \\
\hline$M_{v o l}$ & $=$ & big-M, relacionado com o volume do oleoduto \\
\hline$T_{r e p, p}$ & $=$ & Tempo de repouso mínimo do produto $\mathrm{p}(\mathrm{h})$ \\
\hline$I D_{\max , p}$ & $=$ & Capacidade de armazenagem do produto $p$ (uv) \\
\hline$W o_{i}$ & $=$ & $\begin{array}{l}\text { Volume dos batches que estão inicialmente no oleoduto } \\
\text { (uv) }\end{array}$ \\
\hline TDem $_{k}$ & $=$ & $\begin{array}{l}\text { Escala temporal diária }(k) \text { para atualização da procura de } \\
\text { clientes }(\mathrm{h})\end{array}$ \\
\hline $\operatorname{lots}_{p, l t}$ & $=$ & $\begin{array}{l}\text { Matriz de volumes It de batches possíveis para cada } \\
\text { produto } p \text { (uv) }\end{array}$ \\
\hline $\operatorname{Dem}_{p, k}$ & $=$ & Procura do produto $\mathrm{p}$ no dia $\mathrm{k}$ (uv) \\
\hline sequence $_{p, p^{\prime}}$ & $=$ & $\begin{array}{l}\text { Matriz de sequências possíveis entre pares de produtos } \mathrm{p} e \\
\mathrm{p}^{\prime}\end{array}$ \\
\hline$I D_{p}^{0}$ & $=$ & Inventário inicial do produto p no parque de tanques (uv) \\
\hline$w_{1}, w_{2}, w_{3}$ & $=$ & Pesos dos termos da função objetivo \\
\hline Variáv & $\mathrm{N}_{2}^{2}$ & Negativas \\
\hline$C_{i}$ & $=$ & $\begin{array}{l}\text { Tempo ao qual o batch } i \text { termina de ser injectado no } \\
\text { oleoduto }(\mathrm{h})\end{array}$ \\
\hline$L_{i}$ & $=$ & Duração da injeção do batch $i(h)$ \\
\hline$Q_{i}$ & $=$ & Volume do batch $i$ (uv) \\
\hline$F_{i}^{i^{\prime}}$ & $=$ & $\begin{array}{l}\text { Coordenada volumétrica superior do batch } i \text { enquanto é } \\
\text { injetado o batch } i \text { ' (uv) }\end{array}$ \\
\hline$W_{i}^{i^{\prime}}$ & $=$ & $\begin{array}{l}\text { Fração volumétrica do batch } i \text { ainda no interior do oleoduto } \\
\text { ao injetar o batch i' (uv) }\end{array}$ \\
\hline$D_{i}^{i^{\prime}}$ & $=$ & $\begin{array}{l}\text { Fração volumétrica do batch i descarregada do oleoduto ao } \\
\text { injetar o batch i' (uv) }\end{array}$ \\
\hline$D_{\text {clients, } i}^{i^{\prime}}$ & $=$ & $\begin{array}{l}\text { Volume do batch } i \text { disponibilizado para clientes após } \\
\text { repouso aquando da injeção do batch i' (uv) }\end{array}$ \\
\hline$q d_{p}^{i}$ & $=$ & Procura do produto $p$ enquanto é injetado o batch $i$ (uv) \\
\hline$D V_{i, p}^{i^{\prime}}$ & $=$ & $\begin{array}{l}\text { Fração de volume do batch i de produto } p \text { descarregada do } \\
\text { oleoduto aquando da injeção do batch i' (uv) }\end{array}$ \\
\hline$D V_{c l i e n t s, i, p}^{i^{\prime}}$ & $=$ & $\begin{array}{l}\text { Volume do batch } i \text { de produto } \mathrm{p} \text { disponibilizada para clientes } \\
\text { aquando da injeção do batch i' (uv) }\end{array}$ \\
\hline$I D_{\text {total }, p}^{i}$ & $=$ & $\begin{array}{l}\text { Inventário total do produto } p \text { disponível no parque de } \\
\text { tanques aquando da injeção do batch } i \text { (uv) }\end{array}$ \\
\hline$I D_{p}^{i}$ & $=$ & $\begin{array}{l}\text { Inventário de produto } p \text { disponível para clientes aquando da } \\
\text { injeção do batch } i \text { (uv) }\end{array}$ \\
\hline$T_{\text {set }, i}^{i^{\prime}}$ & $=$ & $\begin{array}{l}\text { Tempo cumulativo de repouso do batch } i \text { aquando da } \\
\text { injeção do batch i' (h) }\end{array}$ \\
\hline
\end{tabular}


$\begin{array}{ll}T_{\text {setp }, i, p}^{i^{\prime}} & =\begin{array}{l}\text { Tempo cumulativo de repouso do batch } i \text { de produto } p \\ \text { aquando da injeção do batch } i^{\prime}(\mathrm{h})\end{array} \\ \text { minid } & =\quad \begin{array}{l}\text { Variável maior que qualquer dos inventários finais de todos } \\ \text { os produtos }\end{array}\end{array}$

- Variáveis Binárias

\begin{tabular}{|c|c|c|}
\hline$y_{i, p}$ & $=$ & O batch i contém o produto $\mathrm{p}$ caso $y_{i, p}=1$ \\
\hline$x_{i}^{i^{\prime}}$ & $=$ & $\begin{array}{l}\text { Uma fração do batch } i \text { pode ser descarregada aquando da } \\
\text { injeção do batch i' caso } x_{i}^{i^{\prime}}=1\end{array}$ \\
\hline$l s_{i, p, l t}$ & $=$ & O batch $i$ tem o volume It do produto $p$ caso $l s_{i, p, l t}=1$ \\
\hline$d m e_{i, k}$ & $=$ & $\begin{array}{l}\text { O dia } k \text { (0 horas) está no intervalo temporal }\left[0, C_{i}\right] \text { caso } \\
\text { dme }_{i, k}=1 .\end{array}$ \\
\hline$d m_{i, k}^{\text {Final }}$ & $=$ & $\begin{array}{l}\text { As } 0 \text { horas do dia } k \text { estão localizadas no intervalo temporal } \\
\left.J_{i-1}, C_{i}\right] \text { caso } d m_{i, k}^{\text {Final }}=1\end{array}$ \\
\hline$x_{\text {set }, i}^{i^{\prime}}$ & $=$ & $\begin{array}{l}\text { O batch } i \text { já efetuou tempo de repouso aquando da injeção } \\
\text { do batch i' caso } x_{\text {set, } i}^{i^{\prime}}=1\end{array}$ \\
\hline$x_{\text {available, } i}^{i^{\prime}}$ & $=$ & $\begin{array}{l}\text { O batch } i \text { já pode ser disponibilizado para clientes aquando } \\
\text { da injeção do batch i' caso } x_{\text {available }, i}^{i^{\prime}}=1\end{array}$ \\
\hline$x_{\text {clients }, i}^{i^{\prime}}$ & $=$ & $\begin{array}{l}\text { O batch } i \text { está disponível para clientes aquando da injeção } \\
\text { do batch i' caso } x_{c l i e n t s, i}^{i^{\prime}}=1\end{array}$ \\
\hline pmatch $_{i}$ & $=$ & $\begin{array}{l}\text { O tempo de paragem do oleoduto ( } T^{\text {stop }} \text { ) é menor que } C_{i} \\
\text { caso } \text { pmatch }_{i}=1\end{array}$ \\
\hline pstop $_{i}$ & $=$ & $\begin{array}{l}\text { A paragem do oleoduto ocorre no intervalo temporal } i \text { caso } \\
\text { pstop }_{i}=1\end{array}$ \\
\hline
\end{tabular}

\subsection{Formulação Matemática do Modelo I}

Por restrições de dimensão do artigo, apenas a Função Objetivo é descrita com detalhe. As restrições do modelo apenas são apresentadas e agrupadas por função. Para maior detalhe consultar Relvas et al. (2006) e Relvas (2008).

- $\quad$ Função Objetivo

$$
\begin{aligned}
& \min \left(w_{1} \times \frac{\sum_{i \in I^{\prime} \in I^{\text {new }}} D_{i}^{i^{\prime}}-\sum_{p \in P} \sum_{k \in K} \operatorname{Dem}_{p, k}}{h_{\max } \times v b_{\max }}-w_{2} \times \frac{\sum_{i \in I^{\text {new }}} L_{i}}{h_{\max }}-w_{3} \times \text { minid }\right) \\
& \sum_{i \in I} \sum_{i^{\prime} \in I^{\text {new }}} D_{i}^{i^{\prime}}-\sum_{p \in P} \sum_{k \in K} \operatorname{Dem}_{p, k} \geq 0
\end{aligned}
$$




$$
\text { minid } \geq\left. I D_{\text {total }, p}^{i}\right|_{i=|I|}
$$

A função objetivo minimiza um conjunto de indicadores de operação que por relacionarem grandezas diferentes se encontram adimensionalizados e com valores restringidos ao intervalo [0,1]. De modo a poder dar-se diferentes pesos a cada indicador, cada termo pode ser multiplicado por um valor $\left(\mathrm{w}_{1}, \mathrm{w}_{2}\right.$ e $\left.\mathrm{w}_{3}\right)$, associados a diferentes modos operacionais. O primeiro termo da função objetivo pretende minimizar a diferença entre o volume total bombeado e o volume total consumido, garantindo com a restrição (1a) que esta diferença é sempre positiva ou nula. O segundo termo maximiza o tempo total de bombagem de produtos. Estes dois termos em conjunto permitem minimizar o caudal de bombagem mas garantindo a reposição de inventário. O caudal é minimizado indiretamente pois por questões de linearidade não é uma variável do modelo. Por fim o último termo maximiza o menor dos inventários finais relativos por produto, por uma estratégia minmax usando a restrição adicional (1b). Assim, existe alguma garantia de flexibilidade deste inventário para inicializar o horizonte temporal seguinte sem que ocorram ruturas de stock.

- $\quad$ Sequenciação de Batches

$$
\begin{array}{ll}
C_{i}-L_{i} \geq C_{i-1} & \forall i \in I^{\text {new }} \\
L_{i} \leq C_{i} & \forall i \in I^{\text {new }} \\
C_{i} \leq h_{\max } & \forall i \in I^{\text {new }}
\end{array}
$$

- Relação entre volume do batch e duração da sua bombagem para o oleoduto

$$
\begin{array}{ll}
v b_{\text {min }} \times L_{i} \leq Q_{i} \leq v b_{\max } \times L_{i} & \min \left(\text { lots }_{p, l t}\right) \\
l_{\text {min }}=\frac{v b_{\text {max }}}{\text { new }} & \\
l_{\text {max }}=\frac{\max \left(\text { lots }_{p, l t}\right)}{v b_{\text {min }}} & \\
\sum_{p} y_{i, p} \times l_{\text {min }} \leq L_{i} \leq \sum_{p} y_{i, p} \times l_{\text {max }} &
\end{array}
$$


- Sequências proibídas

$y_{i-1, p}+y_{i, p^{\prime}} \leq 1+$ sequence $_{p, p^{\prime}} \quad \forall i \in I^{\text {new }}, \quad \forall p, p^{\prime} \in P$

- Limites superior e inferior do batch i no interior do oleoduto $F_{i+1}^{i^{\prime}}+W_{i}^{i^{\prime}}=F_{i}^{i^{\prime}}$

$\forall i \in I, \forall i^{\prime} \in I^{\text {new }}, \quad i^{\prime}>i$

- Gestão das operações que ocorrem no final do oleoduto

$Q_{i}=W_{i}^{i}+D_{i}^{i}$

$\forall i \in I^{\text {new }}$

$F_{i}^{i}=W_{i}^{i}$

$\forall i \in I^{\text {new }}$

$W_{i}^{i^{\prime}}=W_{i}^{i^{\prime}-1}-D_{i}^{i^{\prime}}$

$\forall i \in I, \forall i^{\prime} \in I^{\text {new }}, \quad i^{\prime}>i$

$D_{i}^{i^{\prime}} \leq D_{\max } \times x_{i}^{i^{\prime}}$

$\forall i \in I, \forall i^{\prime} \in I^{\text {new }}, \quad i^{\prime} \geq i$

$F_{i}^{i^{\prime}} \geq \sigma \times x_{i}^{i^{\prime}}$

$\forall i \in I, \forall i^{\prime} \in I^{\text {new }}, \quad i^{\prime} \geq i$

$F_{i+1}^{i^{\prime}-1} \leq \sigma-D_{i}^{i^{\prime}}+\left(1-x_{i}^{i^{\prime}}\right) \times M_{v o l}$

$\forall i \in I, \forall i^{\prime} \in I^{\text {new }}, \quad i^{\prime}>i$

$W_{i}^{i^{\prime}-1} \geq D_{\min } \times x_{i}^{i^{\prime}}$

$\forall i \in I, \forall i^{\prime} \in I^{\text {new }}, \quad i^{\prime}>i$

$D_{i}^{i^{\prime}} \leq W_{i}^{i^{\prime}-1}$

$\forall i \in I, \forall i^{\prime} \in I^{\text {new }}, \quad i^{\prime}>i$

- Restrições de alocação de produtos a batches

$$
\begin{aligned}
& \sum_{p \in P} y_{i, p} \leq 1 \\
& \sum_{p \in P} y_{i, p} \leq \sum_{p \in P} y_{i-1, p} \\
& \sum_{p} y_{i, p}=1
\end{aligned}
$$

$\forall i \in I^{\text {new }}$

$\forall i \in I^{\text {new }}$

$\forall i \in I^{\text {new }}$

- Seleção do volume do batch

$$
\begin{array}{ll}
\sum_{l \in \in T} l s_{i, p, l t}=y_{i, p} & \forall i \in I^{\text {new }}, p \in P \\
Q_{i}=\sum_{p \in P} \sum_{l \in \in T}\left(l_{s_{i, p, l t}} \times \operatorname{lots}_{p, l t}\right) & \forall i \in I^{\text {new }}
\end{array}
$$

- Balanço volumétrico global ao oleoduto ao injetar o batch i'

$$
Q_{i^{\prime}}=\sum_{i \in I, i \leq i^{\prime}} D_{i}^{i^{\prime}}
$$$$
\forall i^{\prime} \in I^{\text {new }}
$$

- Condições iniciais do oleoduto

$$
W_{i}^{i^{\prime}-1}=W o_{i} \quad \forall i \notin I^{\text {new }}, i^{\prime}=\operatorname{first}\left(I^{\text {new }}\right)
$$

- Gestão de inventário no parque de tanques

$$
D V_{i, p}^{i^{\prime}} \leq D_{\text {max }} \times y_{i, p} \quad \forall i^{\prime} \in I^{\text {new }}, p \in P, \quad i^{\prime} \geq i
$$




$$
\begin{array}{ll}
\sum_{p} D V_{i, p}^{i^{\prime}}=D_{i}^{i^{\prime}} & \forall i^{\prime} \in I^{\text {new }}, i^{\prime} \geq i \\
I D_{\text {total }, p}^{i^{\prime}}=I D_{\text {total }, p}^{i^{\prime}-1}+\sum_{i \in I, i \leq i^{\prime}} D V_{i, p}^{i^{\prime}}-q d_{p}^{i^{\prime}} & \\
I D_{\text {total }, p}^{i}=I D_{p}^{0} & i=1, \forall p \in P, i^{\prime} \in I^{\text {new }} \\
I D_{\text {total }, p}^{i^{\prime}} \leq I D_{\text {max }, p} & \forall p \in P, i^{\prime} \in I^{\text {new }} \\
\bullet \quad \text { Gestão da procura de produtos } & \forall i \in I^{\text {new }}, k \in K \\
C_{i} \geq T D e m_{k} \times d m e_{i, k} & \forall i \in I^{\text {new }}, k \in K \\
C_{i} \leq T D e m_{k}+h_{\text {max }} \times d m e_{i, k} & \forall i \in I^{\text {new }}, k \in K \\
d m_{i, k}^{\text {Final }}=d m e_{i, k}-d m e_{i-1, k} & \forall i \in I^{\text {new }}, p \in P \\
q d_{p, i}=\sum_{k \in K} \text { Dem }_{p, k} \times d m_{i, k}^{\text {Final }} &
\end{array}
$$

- Tempo de repouso

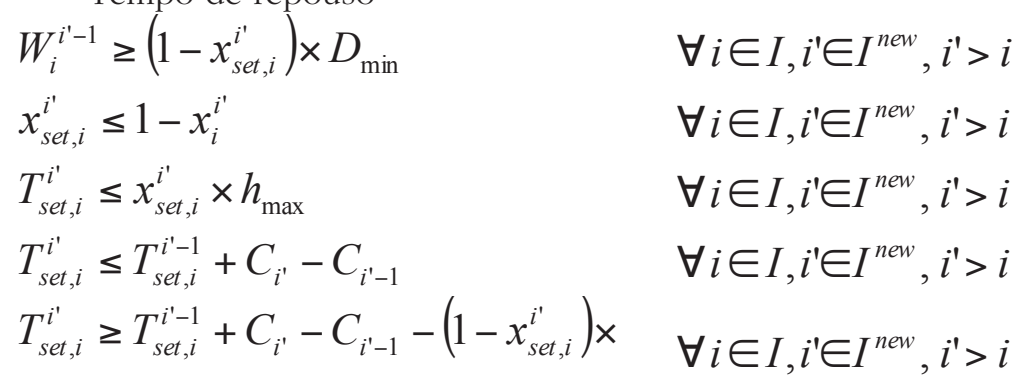

$\sum_{p \in P} T_{s e t p, i, p}^{i^{\prime}}=T_{s e t, i}^{i^{\prime}}$

$\forall i \in I, i^{\prime} \in I^{\text {new }}, i^{\prime}>i$

$T_{\text {setp }, i, p}^{i^{\prime}} \leq y_{i, p} \times h_{\max }$

$\forall i \in I, i^{\prime} \in I^{\text {new }}, i^{\prime}>i$

$T_{\text {setp }, i, p}^{i^{\prime}-1, p} \geq T_{\text {rep }, p} \times\left(y_{i, p}+x_{\text {available }, i}^{i^{\prime}}-1\right)$

$\forall i \in I, i^{\prime} \in I^{\text {new }}, i^{\prime}>i$

$T_{\text {setp }, i, p}^{i^{\prime}-1} \leq T_{\text {rep }, p}+x_{\text {available }, i}^{i^{\prime}} \times h_{\max }$

$\forall i \in I, i^{\prime} \in I^{\text {new }}, i^{\prime}>i$

$x_{\text {clients }, i}^{i^{\prime}}=x_{\text {available }, i}^{i^{\prime}}-x_{\text {available }, i}^{i^{\prime}-1}$

$\forall i \in I, i^{\prime} \in I^{\text {new }}, i^{\prime}>i$

$D_{\text {clients }, i}^{i^{\prime}} \leq Q_{i}$

$\forall i \in I, i^{\prime} \in I^{\text {new }}, i^{\prime}>i$

$D_{\text {clients }, i}^{i^{\prime}} \geq Q_{i}-\left(1-x_{\text {clients }, i}^{i^{\prime}}\right) \times D_{\max }$

$\forall i \in I, i^{\prime} \in I^{\text {new }}, i^{\prime}>i$

$D_{\text {clients }, i}^{i^{\prime}} \leq x_{\text {clients }, i}^{i^{\prime}} \times D_{\max }$

$\forall i \in I, i^{\prime} \in I^{\text {new }}, i^{\prime}>i$ 


$$
\begin{array}{ll}
I D_{p}^{i^{\prime}}=I D_{p}^{i^{\prime}-1}+\sum_{i \in I, i \leq i^{\prime}} D V_{c l i e n t s, i, p}^{i^{\prime}}-q d_{p}^{i^{\prime}} & \forall p \in P, i^{\prime} \in I^{\text {new }} \\
I D_{p}^{i}=I D_{p}^{0} & i=1, \forall p \in P \\
I D_{p}^{i^{\prime}} \leq I D_{\max , p} & \forall p \in P, i^{\prime} \in I^{\text {new }} \\
\sum_{p} D V_{\text {clients }, i, p}^{i^{\prime}}=D_{\text {clients }, i}^{i^{\prime}} & \forall i \in I, i^{\prime} \in I^{\text {new }}, i^{\prime}>i \\
D V_{\text {clients }, i, p}^{i^{\prime}} \leq D_{\text {max }} \times y_{i, p} & \forall i \in I, i^{\prime} \in I^{\text {new }}, p \in P, i^{\prime}>i
\end{array}
$$

- Paragens do Oleoduto

$C_{i-1} \geq T^{\text {stop }} \times$ pmatch $_{i-1} \quad \forall i \in I^{\text {new }}$

pstop $_{i}=$ pmatch $_{i}-$ pmatch $_{i-1}$

$$
\forall i \in I^{\text {new }}
$$

$C_{i} \geq C_{i-1}+L_{i}+\left(T^{\text {start }}-T^{\text {stop }}\right) \times$ pstop $_{i}$

$$
\forall i \in I^{\text {new }}
$$

- Restrições Auxiliares

$$
\begin{array}{ll}
F_{i}^{i^{\prime}} \geq F_{i}^{i^{\prime}-1} & \forall i \in I, \forall i^{\prime} \in I^{\text {new }}, \quad i^{\prime}>i \\
F_{i}^{i^{\prime}}-W_{i}^{i^{\prime}} \geq F_{i}^{i^{\prime}-1}-W_{i}^{i^{\prime}-1} & \forall i \in I, \forall i^{\prime} \in I^{\text {new }}, \quad i^{\prime}>i \\
F_{i}^{i^{\prime}} \geq W_{i}^{i^{\prime}} & \forall i \in I, \forall i^{\prime} \in I^{\text {new }}, \quad i^{\prime} \geq i \\
\sum_{i \in I, i \leq i^{\prime}} D_{i}^{i^{\prime}}=\sum_{p \in P} \sum_{l i \in \in T}\left(l s_{i, ' p, l t} \times \text { lots }_{p, l t}\right) & \forall i^{\prime} \in I^{\text {new }} \\
\sum_{i \in I^{\text {eew }}}^{i^{\prime \prime}} d m_{i, k}^{\text {Final }}=1 & k \in K \\
\sum_{i^{\prime \prime} \in I^{\text {Ine }}, i^{\prime} \geq i}^{i_{i}^{i^{\prime \prime}} \geq x_{\text {set }, i}^{i^{\prime}}} & \\
& k \in K
\end{array}
$$$$
\forall i \in I^{\text {new }}, i^{\prime} \in I^{\text {new }}, i>i^{\prime}
$$$$
\forall i \in I, \forall i^{\prime} \in I^{\text {new }}, \quad i^{\prime}>i
$$

\section{Validação do Método Desenvolvido}

Nesta secção serão brevemente apresentados resultados que ilustram a utilização do sistema desenvolvido. Para tal, foi adotado um exemplo real baseado na operação da CLC e com horizonte temporal de um mês. De notar que para o caso de estudo aqui apresentado apenas são considerados 6 produtos, sendo este o lote de produtos em vigor à data da recolha de dados. 
Todos os modelos desenvolvidos foram implementados em GAMS 22.4 (Brooke et al., 2006) e solucionados usando o CPLEX 10.0. instalado num Pentium D820 com 2 GB RAM. Foi assumido como critério de paragem uma das seguintes opções: duas horas de computação ou a obtenção de uma solução com gap relativo inferior a $5 \%$.

Os resultados serão apresentados sequencialmente, primeiro na definição e aplicação de sequências de bombagem no Modelo I, desenvolvimento do plano de gestão de inventário com o modelo II e escalonamento reativo.

\subsection{Definição de Sequências de Bombagem e Escalonamento com o Modelo I}

O primeiro passo para usar a metodologia passa por definir sequências de produtos a serem bombeadas no oleoduto. Foram propostas cinco sequências usando a heurística de inicialização, com números de batches a bombear que variam entre 33 e 41 . Estas sequências foram construídas com o pressuposto que os batches dos diferentes produtos bombeados deverão repor o volume previsto a ser consumido no mês em estudo. Após obter as sequências, estas foram testadas no Modelo I, tendo-se obtido os resultados apresentados na Tabela 2. Verifica-se que a sequência menor torna a solução inviável (poderá não permitir manter o inventário nos limites admissíveis apesar de prever a reposição do volume consumido), enquanto as restantes têm solução. Apenas a solução para 35 batches requereu um tempo de computação inferior a duas horas para cumprir o critério de paragem imposto. Nas restantes, o gap relativo é inferior a 5\% pois é adicionada a possibilidade de o CPLEX aplicar a opção de polishing à solução encontrada durante alguns segundos.

Tabela 2 - Comportamento do Modelo I para o cenário em estudo

\begin{tabular}{|l|l|l|l|l|l|}
\hline \multicolumn{1}{|c|}{ Sequência } & \multicolumn{1}{c|}{$\mathbf{3 3}$} & \multicolumn{1}{c|}{$\mathbf{3 5}$} & \multicolumn{1}{c|}{$\mathbf{3 7}$} & \multicolumn{1}{c|}{$\mathbf{3 9}$} & \multicolumn{1}{c|}{$\mathbf{4 1}$} \\
\hline Variáveis contínuas & 19088 & 21228 & 23480 & 25844 & 28320 \\
\hline Variáveis binárias & 4685 & 5111 & 5553 & 6011 & 6485 \\
\hline Restrições & 34101 & 38030 & 42171 & 46524 & 51089 \\
\hline Nós explorados & - & 1082 & 16349 & 9807 & 73745 \\
\hline Iterações & - & 797306 & 10139853 & 9211173 & 6600480 \\
\hline CPU (s) & 33.578 & 521.640 & 7230.562 & 7230.781 & 7231.531 \\
\hline Função Objectivo & - & -2.229111 & -2.231544 & -2.231544 & -2.234025 \\
\hline Gap Relativo (\%) & - & 0.11 & 0.52 & 0.52 & 0.41 \\
\hline
\end{tabular}


$\mathrm{Na}$ Tabela 3 incluem-se os resultados operacionais que cada uma das sequências gerou ao ser implementada no Modelo I. Incluiu-se também na última coluna da tabela os valores calculados para os mesmos indicadores tendo como base a solução proposta pelos chefes de turno da CLC.

Tabela 3 - Resultados Operacionais do Modelo I para o cenário em estudo

\begin{tabular}{|l|l|l|l|l|l|l|}
\hline \multicolumn{1}{|c|}{ Sequência } & \multicolumn{1}{c|}{$\mathbf{3 3}$} & \multicolumn{1}{c|}{$\mathbf{3 5}$} & \multicolumn{1}{c|}{$\mathbf{3 7}$} & \multicolumn{1}{c|}{$\mathbf{3 9}$} & \multicolumn{1}{c|}{$\mathbf{4 1}$} & CLC (38) \\
\hline Caudal Médio (uv/h) & - & 511 & 511 & 511 & 510 & 558 \\
\hline$\Delta$ Inventário (uv) & - & +380 & +680 & +680 & +280 & +19580 \\
\hline $\begin{array}{l}\text { Utilização do } \\
\text { Oleoduto (\%) }\end{array}$ & - & 99 & 99 & 99 & 99 & 95 \\
\hline $\begin{array}{l}\text { Nível de Inventário } \\
\text { Final (\%) }\end{array}$ & - & 55 & 56 & 56 & 55 & 65 \\
\hline $\begin{array}{l}\text { Inventário Mínimo } \\
\text { (\%) }\end{array}$ & - & $16.4(\mathrm{P} 3)$ & $18.4(\mathrm{P} 4)$ & $18.8(\mathrm{P} 3)$ & $21.2(\mathrm{P} 3)$ & $5.3(\mathrm{P} 3)$ \\
$\begin{array}{l}\text { Inventário Mínimo } \\
\text { Final (\%) }\end{array}$ & - & $51.7(\mathrm{P} 1)$ & $52.5(\mathrm{P} 1)$ & $52.5(\mathrm{P} 1)$ & $52.5(\mathrm{P} 1)$ & $20.5(\mathrm{P} 3)$ \\
\hline
\end{tabular}

Observando a Tabela 3 verifica-se que todas as soluções viáveis apresentam um caudal médio inferior ao proposto pela solução real. Tal deve-se ao facto de o modelo minimizar o caudal de bombagem mas com a ressalva que deve ser reposto o volume consumido, sendo que as soluções propostas apenas transportam algumas uv's a mais face ao consumido no parque de tanques da CLC. A utilização do oleoduto e o nível de inventário final global também se mantiveram semelhantes entre as soluções propostas. As duas últimas linhas incluem outros indicadores de inventário que são referentes a produtos e não ao inventário global. O inventário mínimo contabiliza o nível relativo de inventário que qualquer um dos produtos verificou ao longo do horizonte temporal, sendo o produto P3 aquele que mais frequentemente apresenta o menor valor. Além disso, o valor mais baixo verificou-se na solução real. Estes valores são essenciais para verificar a flexibilidade da solução, pois caso ocorram situações imprevistas, um nível de inventário mais baixo tem menor flexibilidade para acomodar alterações. Já no caso dos inventários finais, também a solução real é menos flexível. Neste caso trata-se de flexibilizar o início do próximo período de operação. 
A sequência selecionada para este mês é a sequência com 41 batches, uma vez que reúne o maior conjunto de indicadores operacionais com melhores valores. Nesta sequência, a título exemplificativo, são bombeados 11 batches do produto $\mathrm{P} 1,5$ batches de $\mathrm{P} 2,1$ batch de $\mathrm{P} 3,9$ batches de $\mathrm{P} 4,10$ batches de P5 e 5 batches de P6.

\subsection{Gestão de Inventário - Modelo II}

Com a sequência selecionada usou-se o Modelo II para obter um escalonamento mais detalhado da $1^{\text {a }}$ semana de operação, cujos resultados se encontram nas tabelas 4 e 5. Para esta solução considerou-se que os 41 batches a bombear representam em média 1.32 batches por dia. Em 7 dias de operação seriam bombeados 9.26 batches. Assim, assumiu-se um valor máximo de 15 batches e, caso cada batch fosse usado na sequência, seguiria a sequência prédeterminada com a heurística de inicialização. Os resultados foram obtidos em menos de 4 minutos de computação, com um valor de função objetivo penalizado face aos valores obtidos pelo Modelo I. De notar que a função objetivo (1) usou pesos para $\mathrm{w}_{1}$ de 3, para $\mathrm{w}_{2}$ de 2 e para $\mathrm{w}_{3}$ de 0,5 para os diferentes termos (nesta ordem). Os resultados computacionais encontram-se na Tabela 4 .

Tabela 4 - Comportamento do Modelo II para a $1^{\text {a }}$ semana do cenário em estudo (Sequência com 41 batches)

\begin{tabular}{|l|l|}
\hline & Modelo II \\
\hline Variáveis contínuas & 5311 \\
\hline Variáveis binárias & 2199 \\
\hline Restrições & 11474 \\
\hline Nós explorados & 7429 \\
\hline Iterações & 462125 \\
\hline CPU (s) & 191.953 \\
\hline Função Objectivo & -1.969278 \\
\hline Gap Relativo (\%) & 0.04 \\
\hline
\end{tabular}

No caso dos resultados operacionais apresentados na Tabela 5, verifica-se um ligeiro agravamento dos indicadores analisados quando se passa do Modelo I para o Modelo II (por exemplo, aumento do caudal médio), 
implicando algum ajustamento nos resultados uma vez que se tem o sistema mais detalhado. De qualquer forma, todos os indicadores são ainda melhores que os indicadores obtidos na solução real. De notar que aqui apenas se mostram os resultados operacionais para o Modelo I referentes à $1^{\text {a }}$ semana, referentes aos resultados obtidos da otimização mensal.

Tabela 5 - Resultados Operacionais do Modelo II para a primeira semana do cenário em estudo

\begin{tabular}{|l|l|l|l|}
\hline Solução & Modelo II & Modelo I & CLC (38) \\
\hline Caudal Médio (UV/h) & 537.43 & 527.84 & 550.00 \\
\hline$\Delta$ Inventário (UV) & +30 & -171 & -23063 \\
\hline Utilização do Oleoduto (\%) & 92.59 & 92.59 & 79.76 \\
\hline Nível de Inventário Final (\%) & 55.68 & 55.05 & 42.88 \\
\hline Inventário Mínimo (\%) & $23.63(\mathrm{P} 6)$ & $23.58(\mathrm{P} 3)$ & $18.19(\mathrm{P} 6)$ \\
\hline Inventário Mínimo Final (\%) & $23.65(\mathrm{P} 3)$ & $23.58(\mathrm{P} 3)$ & $23.89(\mathrm{P} 3)$ \\
\hline
\end{tabular}

\subsection{Escalonamento Reativo}

Além dos resultados iniciais, ou seja, planeamento inicial, também se acompanhou o desenrolar deste mês em detalhe a fim de registar e documentar todas as alterações passíveis de reajustar o planeamento em vigor. Ao todo houve necessidade de usar o método de planeamento reativo em 5 ocasiões distintas. De notar que o método desenvolvido permite que mais do que uma das situações seja incorporada no mesmo reescalonamento. Por exemplo, a última revisão do planeamento incluiu novas previsões de clientes referentes à última semana (mais detalhadas que as originais), aumento de capacidade de um dos produtos devido à entrada em funcionamento de um novo tanque e inclusão de uma paragem obrigatória no oleoduto para ligar o novo tanque à linha de abastecimento do oleoduto.

Neste caso, a função objetivo original foi alterada, incluindo agora termos de penalização. Estas penalizações permitem que sejam minimizadas alterações ao planeamento original. Consideraram-se alterações de sequência e alterações de volume de batches. Ambas as ocorrências são controladas por variáveis binárias e, como tal, incluíram-se na função objetivo dois termos que penalizam alterações ao valor inicial de cada uma destas variáveis. Os pesos 
destes termos são unitários. No entanto, cada alteração conta com o valor de 1 , o que poderá prejudicar bastante o valor mínimo da função objetivo. Em termos de computação, os critérios de paragem usados foram os mesmos que na aplicação dos Modelos I e II. Os resultados computacionais dos vários reescalonamentos encontram-se na Tabela 6.

Verifica-se que conforme se avança no horizonte temporal, o facto de se ter um menor período para refazer o planeamento, contribui largamente para que o tempo de computação diminua drasticamente. Em termos de alterações, a primeira revisão do planeamento (R1) foi aquela que teve mais alterações. Neste caso, a situação que ocorreu implicava, ela própria, alteração da sequência de produtos por falta de inventário na refinaria. Em termos de dimensão do modelo, esta permanece relativamente estável porque, apesar de apenas se reajustar uma parte do planeamento, todo o mês é contabilizado. A parte inicial do planeamento é fixada. A solução ótima é obtida para as três últimas revisões, enquanto na primeira não se atingiu o gap relativo desejado ao final de duas horas de computação.

Tabela 6 - Resultados computacionais para o reescalonamento

\begin{tabular}{|l|l|l|l|l|l|l|}
\hline & \multicolumn{1}{|c|}{$\begin{array}{c}\text { Plano } \\
\text { Inicial }\end{array}$} & \multicolumn{1}{|c|}{ R1 } & \multicolumn{1}{|c|}{ R2 } & \multicolumn{1}{|c|}{ R3 } & \multicolumn{1}{|c|}{ R4 } & \multicolumn{1}{|c|}{ R5 } \\
\hline $\begin{array}{l}\text { Variáveis } \\
\text { contínuas }\end{array}$ & 28320 & 28320 & 28320 & 28320 & 28316 & 28356 \\
\hline $\begin{array}{l}\text { Variáveis } \\
\text { binárias }\end{array}$ & 6485 & 5625 & 6358 & 6230 & 6230 & 6014 \\
\hline Restrições & 51089 & 51089 & 51089 & 51090 & 51076 & 51937 \\
\hline Nós explorados & 73745 & 438395 & 51880 & 558 & 2182 & 1 \\
\hline Iterações & 6600480 & 9537433 & 1407067 & 6043 & 31084 & 69 \\
\hline CPU (s) & 7231.5 & 7230.6 & 1294.468 & 15.4 & 29.1 & 1.8 \\
\hline Função Objectivo & -2.2340 & 5.9160 & -1.0992 & -2.0992 & -0.0992 & -2.0240 \\
\hline Gap Relativo (\%) & 0.41 & 8.07 & 4.89 & 0.00 & 0.00 & 0.00 \\
\hline $\begin{array}{l}\text { Número de } \\
\text { Penalizações }\end{array}$ & - & 8 & 1 & 0 & 2 & 0 \\
\hline
\end{tabular}

Por fim, na Figura 6 mostra-se a comparação entre os perfis de inventário após a última revisão feita a partir da solução proposta neste caso de estudo pelo Modelo I e a solução adotada na CLC. Apesar de os perfis não serem semelhantes, os padrões seguidos e as ordens de grandeza são comparáveis. 
Os desfasamentos nas receções de produto (declives positivos) são devidos ao produto ser recebido em pontos temporais diferentes, devido a se terem sequências e volumes bombeados diferentes.
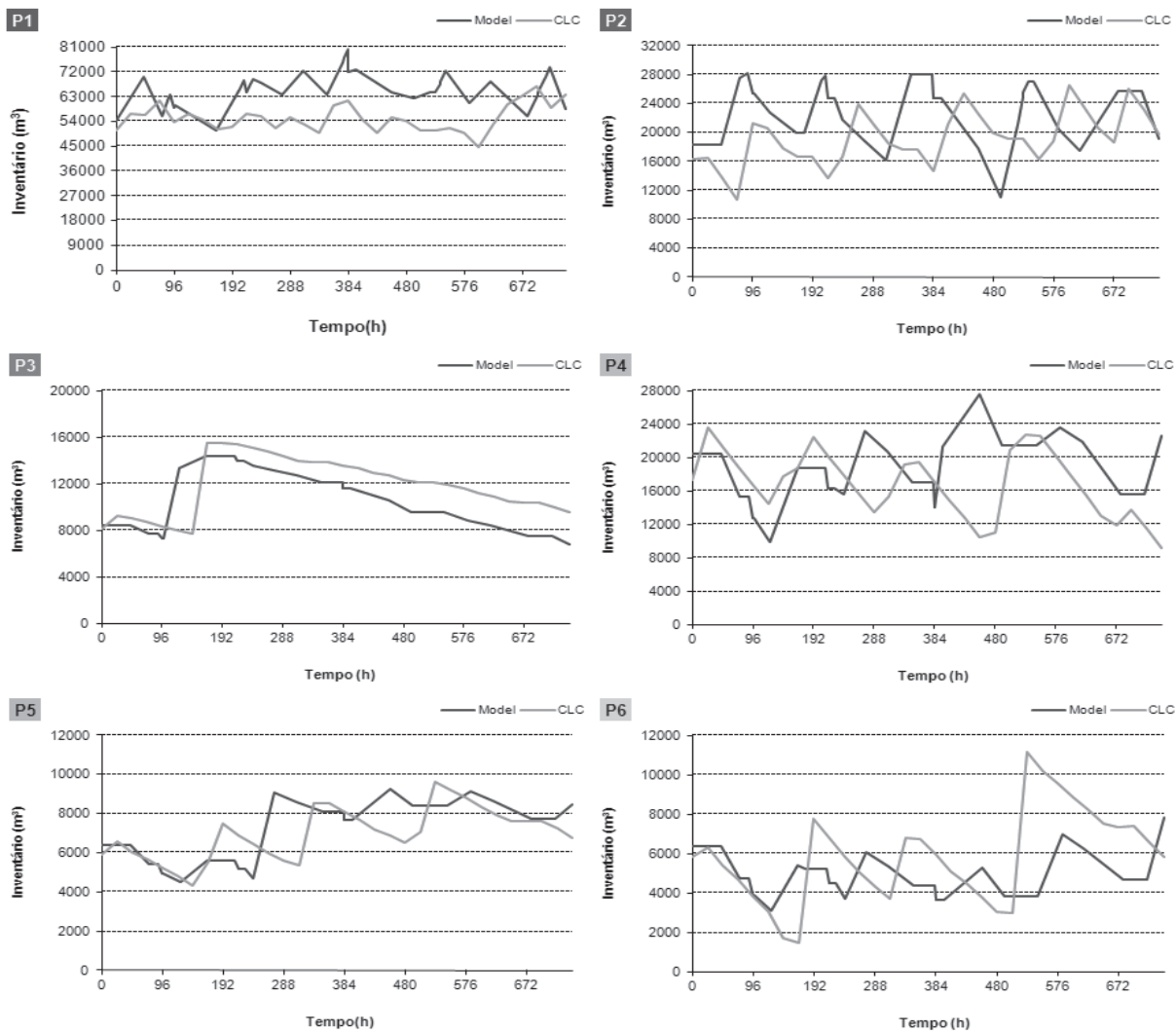

Figura 6 - Perfis de Inventário por produto após revisões: Solução Proposta vs. Real

\section{Transferência de Tecnologia}

Com a finalidade de permitir que um utilizador com conhecimento sobre o sistema mas sem conhecimento sobre a metodologia de solução desenvolvida possa usufruir de uma solução otimizada em detrimento de uma solução baseada em conhecimento pessoal foi desenvolvida uma interface para o sistema descrito. Esta interface e sistema de apoio à decisão associado permitiu não só consolidar a sistematização da solução desenvolvida, através da ligação a bases de dados com a informação necessária para correr a solução, mas também sistematizar o armazenamento de resultados obtidos. 
Esta interface foi desenvolvida por um aluno de mestrado do IST de Engenharia Informática, sob orientação da restante equipa do IST. O software ao ser desenvolvido foi sendo apresentado na CLC para customização conjunta da ferramenta.

\subsection{Desenvolvimento do Software de Interface}

O ponto inicial para a fase de desenvolvimento do software passou pela compreensão do tipo de interface mais adequada para a futura aplicação. Neste caso, identificou-se que a interface requerida é direcionada para o utilizador. Neste ponto, foi necessário confrontar o software onde foram desenvolvidos os modelos base - GAMS - e o formato da interface. Selecionou-se um formato de aplicação baseada em browser (aplicação Web). Esta permite acessibilidade a qualquer utilizador, bastando para tal que a aplicação esteja sediada unicamente num servidor acedido remotamente. Além disso, este tipo de aplicação elimina potenciais incompatibilidades de sistema operativo e os privilégios a atribuir a cada utilizador podem ser definidos na aplicação. Todos os dados são assim instalados apenas do lado do servidor, o que simplifica também a fácil manutenção e atualizações.

Como o GAMS é uma aplicação multiplataforma, a única restrição para o programador é o sistema operativo do servidor. Esta restrição é essencial no processo de escolha da linguagem de programação e no sucesso global da aplicação. Outra restrição é o próprio programador, que deve conhecer profundamente a linguagem a adotar. Por fim, existe o critério financeiro, que neste caso direcionou a escolha para uma linguagem de livre acesso e gratuita.

Outras ferramentas essenciais são as bibliotecas desenvolvidas por terceiros. Existe uma larga variedade de bibliotecas e muitas delas também de acesso livre. Assim, a qualidade do projeto pode ser assegurada usando este tipo de bibliotecas. Um bom exemplo é a necessidade de gerar páginas Web compatíveis com todos os browsers.

Com esta base, a escolha da linguagem de programação e bibliotecas a utilizar é essencial para assegurar a qualidade e sucesso da aplicação a desenvolver. Para a interface desenvolvida foram escolhidas várias aplicações 
de acesso livre, tais como JBoss RichFaces, JBoss Ajax4jsf, JBoss Seam 2.1.1, JBoss Tools 3.0.0.CR1, EJB3, JFreeCharts and MySql 5.1.

\subsection{Instalação do Software no Cliente}

O desenvolvimento da interface para um método de escalonamento com utilização num ambiente empresarial real requer a análise de várias questões que vão desde a sua arquitetura conceptual até à implementação real ou integração de sistemas e validação. O principal objetivo para o processo de desenvolvimento da interface e transferência de tecnologia foi garantir a sua fiabilidade e a facilidade de utilização, sem esquecer que a navegação e os resultados apresentados pela interface tenham significado para os utilizadores. O objetivo da ferramenta no seu global sempre foi a obtenção de boas soluções para o problema real em estudo e em tempo de computação reduzido.

A implementação em ambiente real de uma ferramenta deste tipo requer um elevado nível de interação com o cliente e uma clara definição temporal dos recursos necessários em cada fase da passagem de tecnologia. O nível inicial requer o levantamento dos sistemas de informação presentes no cliente, nomeadamente ao nível da recolha de dados a usar pelo software em desenvolvimento, formato de relatórios de resultados, manutenção de base de dados, formatação, segurança, requisitos em termos de recursos em sistemas de informação, compatibilidade ou ainda procedimentos do cliente a ter em conta. Também se deve pensar na manutenção futura, que pode incluir não só a atualização da interface mas também das metodologias de resolução adotadas (modelos ou heurísticas). Finalmente, a aplicabilidade da ferramenta desenvolvida deve ser testada no cliente, usando os seus dados e limites temporais reais, para comparação dos resultados com aqueles obtidos pelo método de planeamento até então em vigor.

\subsection{Avaliação da Utilização da Solução Real}

A interface foi instalada na CLC durante o ano de 2010, tendo passado pelas várias fases descritas na secção anterior. O processo de instalação permitiu atualizar e corrigir questões pontuais de utilização e modificar algum aspeto criticado e discutido junto do cliente. O processo geral baseou-se sempre numa 
proposta por parte da equipa da CLC que era apresentada e instalada posteriormente na CLC e, após algum tempo de teste e validação, era atualizada ou alterada para um formato acordado entre as partes.

O processo de validação da ferramenta desenvolvida permitiu não só o melhoramento da interface mas também dos próprios modelos. Algumas das soluções obtidas nos testes de validação mostraram que para operacionalizar os resultados obtidos seria necessário melhorar o modelo base, nomeadamente ao nível da representação do sistema, hipóteses base de construção, simplificações e estratégias de modelação. Um exemplo é a escala de tempo adotada. Esta escala depende do final da bombagem de cada batch, que tem, conforme o produto envolvido, diferentes durações de bombagem. Uma vez que qualquer outra operação no sistema só pode ser atualizada ao final de cada um destes intervalos, no caso dos intervalos maiores existe pouca flexibilidade operacional para as restantes operações.

O Modelo II ainda não foi incorporado na ferramenta atualmente implementada no cliente. Em alternativa, foi construído um algoritmo que distribui os produtos bombeados pelos tanques disponíveis, permitindo analisar dessa forma os recursos a gerir na CLC ao longo do horizonte temporal. Este algoritmo segue as mesmas regras usadas pelos chefes de turno da CLC na gestão de inventário.

Os dados do cenário em estudo a introduzir pelo utilizador incluem o horizonte temporal para o escalonamento, o inventário inicial disponível por produto e as previsões de procura diária por produto. Este último dado foi integrado com bases de dados já disponíveis na empresa.

Em seguida a heurística de sequenciação é aplicada ao cenário em estudo disponibilizando ao utilizador várias sequências possíveis de produtos a bombear. O utilizador pode selecionar quais das sequências vai testar e definir um tempo máximo de computação para obter uma solução do Modelo I com cada sequência. Quando toda a execução termina, os resultados são visionados a partir das páginas de resultados específicos (Figuras 7 e 8) podendo-se aceder ainda a uma página de resumo dos resultados (Figura 9), que contém uma breve descrição de cada solução obtida por sequência, incluindo o nome da sequência, o estado final do modelo, o tempo de computação e data de 
computação. Além dos resultados computacionais, esta página também mostra resultados operacionais. Estes podem apoiar a decisão sobre qual a sequência que deve ser adotada. Estes resultados são ilustrados por indicadores que incluem o caudal médio de bombagem (que se pretende baixo, pois indiretamente minimiza o consumo energético), duração de paragens, caso existam (as paragens, a menos que obrigatórias, são indesejáveis, pois permitem que a interface entre os produtos se alargue), balanço entre consumo no parque e volume reabastecido pelo oleoduto e, por fim, o nível de inventário global final.

Os resultados de cada sequência podem ser acedidos pela página resumo e incluem os perfis de inventário por produto (Figura 7), o perfil de caudal de bombagem e o escalonamento da bombagem (Figura 8). Este último tem informação sobre a sequência de produtos, os volumes de cada batch, os instantes temporais de início e fim de cada bombagem de um batch, os instantes iniciais e finais de cada descarga de um batch, e os tempos em trânsito de cada batch.

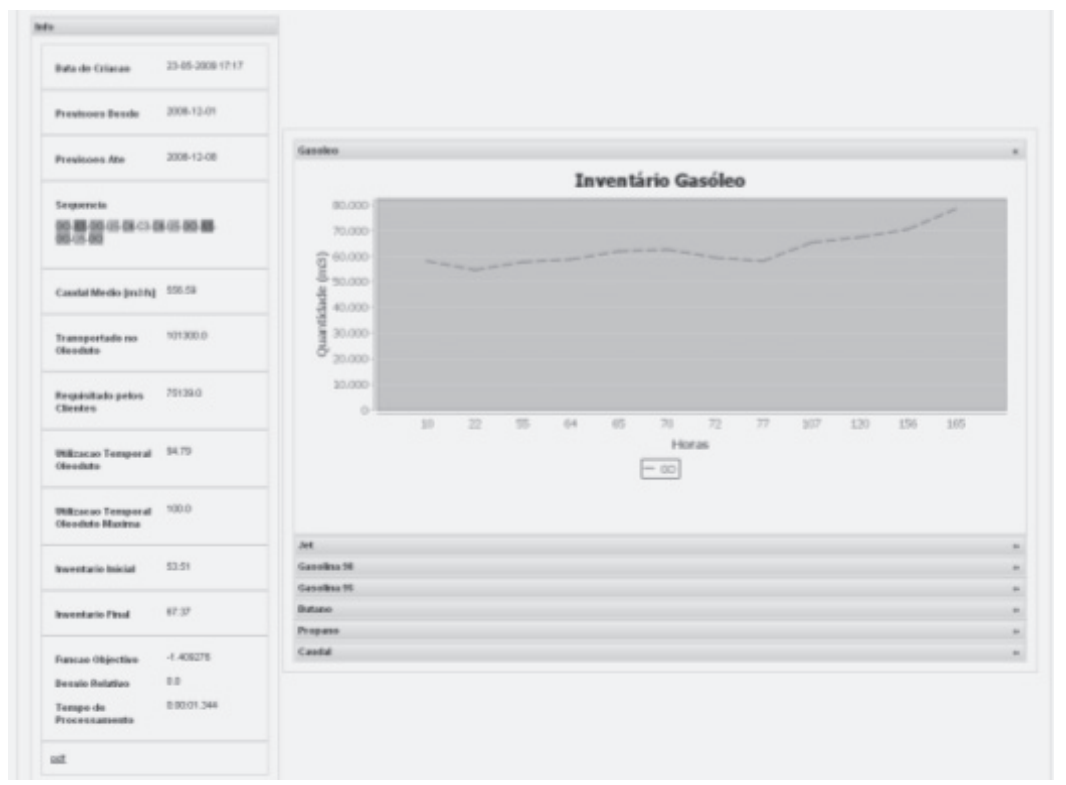

Figura 7 - Página de resultados 1: Perfis de Inventário. 


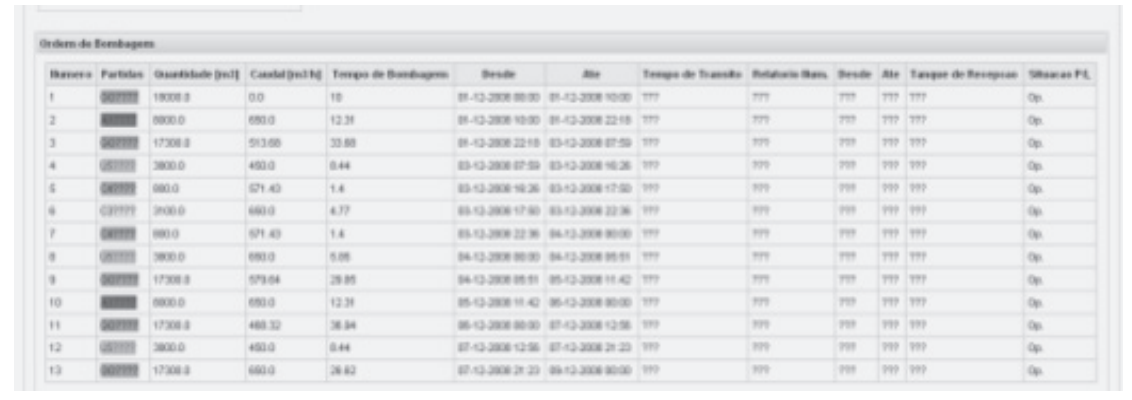

Figura 8 - Página de resultados 2: Sequência de Bombagem

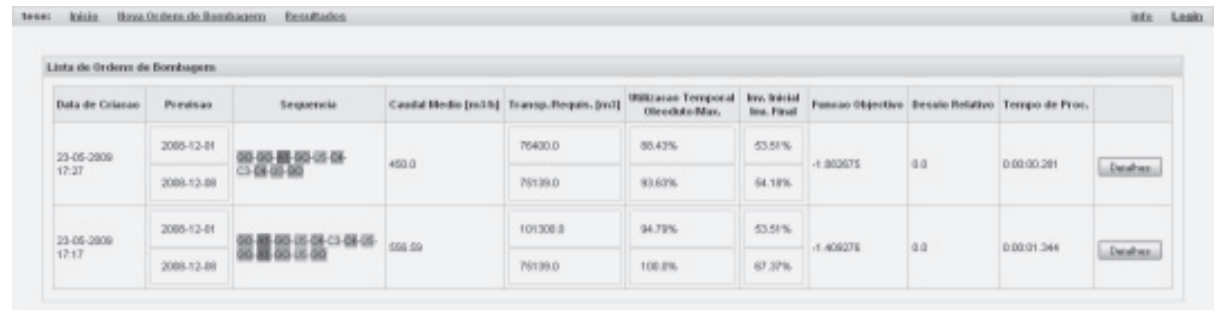

Figura 9 - Página de resumo de resultados

\section{Conclusões e Direções Futuras}

O presente estudo de caso pretende ilustrar a aplicação de técnicas de investigação operacional na resolução de um caso real de elevada complexidade - transporte multiproduto por oleoduto e gestão de inventário num parque de tanques. Importa referir que para a resolução deste caso a existência de uma forte colaboração entre a empresa, fornecedora do caso, e a comunidade académica que desenvolveu as metodologias de modelação e resolução foi essencial. Como resultado ambas as equipas envolvidas e as instituições beneficiaram positivamente em termos de resultados. Conclui-se que é necessário dedicar tempo e os recursos humanos necessários e interdisciplinares para que uma parceria deste tipo alcance o sucesso desejado. O desenvolvimento do método base para o sistema de apoio à decisão requereu conhecimentos de Investigação Operacional e Process Systems Engineering, enquanto o desenvolvimento da interface com o utilizador requer conhecimentos de Engenharia Informática. 
No que respeita à contribuição científica, os modelos MILP desenvolvidos têm uma componente inovadora no que respeita à integração do transporte de produtos por oleoduto multiproduto com a gestão de inventário destes mesmos produtos. Tal abordagem permite contribuir cientificamente não só para a área das cadeias de abastecimento de petróleo, nomeadamente escalonamento de oleodutos, mas também para a área de Enterprise-Wide Optimization (Grossmann, 2005), onde o foco está em integrar diferentes níveis de decisão, processos/operações e metodologias de solução. No caso da modelação da operação do oleoduto o trabalho individualiza-se por se focar em soluções para prazos temporais intermédios (um mês). No caso específico da gestão de inventário, o trabalho desenvolvido é dos primeiros a considerar a operação de um parque de tanques, onde cada tanque segue um ciclo de operações, sendo cada estado e a transição entre estados modelada.

No ponto atual em que se encontra a colaboração já foi transferido para a empresa o software desenvolvido. No entanto, verifica-se que o ciclo de colaboração tem potencial para continuar. As principais forças motrizes para que a colaboração continue são não só a validação e atualização do software, mas também a incorporação de novas ideias ou métodos com melhores resultados para o problema em questão. Tal justifica-se por dois motivos: a dinâmica do próprio sistema em estudo, que é altamente dependente de várias externalidades, e a evolução científica na área em geral.

Neste ponto, é importante referir algumas direções futuras. A equipa do IST desenvolveu recentemente um modelo para a operação do oleoduto que permite obter soluções para o mesmo horizonte temporal mas que não recorre a soluções híbridas com heurísticas (Relvas et al., 2012). Além de ser um modelo holístico no que respeita à obtenção de solução, permite obter soluções em tempo comparável à solução anterior. Este modelo carece ainda de mais validação para aferir a sua adequação ao problema real.

Outro ponto com potencial para melhoria é a representação da gestão de inventário no parque de tanques, de modo a que o modelo integrado de oleoduto e parque de tanques possa ser optimizador também para períodos de um mês (Relvas, 2008). 
Por fim, existe ainda potencial para se melhorar a modelação integrada a fim de permitir uma utilização flexível e adaptada à realidade atual, uma vez que neste momento se verifica ainda que existe pouca flexibilidade no modelo. Tal deve-se ao facto de se ter adotado uma única escala temporal sob a qual todos os eventos ocorrem no sistema. Dado que se estão a considerar operações diferentes, a especificidade das várias ocorrências também é diferente. Tal implica que haja mais pontos temporais de avaliação do sistema, ou seja, ou uma escala mais detalhada ou um outro tipo de escala temporal, mas que não adicione complexidade ao método de solução.

\section{Agradecimentos}

Os autores agradecem todo o apoio financeiro e operacional disponibilizado pela CLC, através dos Projetos de Cooperação Científico Tecnológica, celebrados entre a CLC e o IST, e a Bolsa de Doutoramento em Empresas SFRH/BDE/15523/2004, em parceria com a FCT.

\section{BibiografiA}

BOschetTO, S. N.; Magatão, L.; Brondani, W. M.; Neves, F., Jr.; Arruda, L. V. R.; BarbosaPóvoa, A. P. F. D.; Relvas, S. (2010). An Operational Scheduling Model to Product Distribution through a Pipeline Network. Industrial \& Engineering Chemistry Research, 49, 5661-5682;

BROOKE, A.; Kendrick, D.; Meeraus, A.; Raman, R. (2006). GAMS — A User's Guide; GAMS Development: Washington, DC;

CAFARO, D. C., Cerdá, J., (2004), Optimal Scheduling of Multiproduct Pipeline Systems using a Non-Discrete MILP Formulation, Comput. Chem. Eng., 28 2053-2068;

CAFARO, D. C., Cerdá, (2008), Dynamic scheduling of multiproduct pipelines with multiple delivery due dates, Comput. Chem. Eng., 32, 728-753;

CLC (2011), Site Oficial da CLC, Consultado em Janeiro de 2012 em www.clc.pt;

EUROSTAT POCKET BOOK (2008), Energy, transport and environment indicators, 78-79;

GROSSMANN, I. (2005), Enterprise-wide Optimization: A New Frontier in Process Systems Engineering. AIChE Journal, 51, 1846-1857;

MAGATÃO, L., Arruda, L. V. R., Neves, Jr F., (2004), A Mixed Integer Programming for Scheduling Commodities in a Pipeline, Comput. Chem. Eng., 28 171-185;

MÁS, R., Pinto, J.M. (2004), A Mixed-Integer Optimization Strategy for Oil Supply in Distribution Complexes, Opt. Eng., 4, 23-64;

NORELAND, J. (2008) Eurostat Statistics in Focus: Transport, 35;

REJOWSKI, Jr. R., Pinto, J. M., (2004), Efficient MILP Formulations and Valid Cuts for Multiproduct Pipeline Scheduling, Comput. Chem. Eng., 28, 1511-1528; 
REJOWSKI, Jr. R., Pinto, J. M., (2008), A novel continuous time representation for the scheduling of pipeline systems with pumping yield rate constraints, Comput. Chem. Eng., 32, 10421066 ;

RElvaS, S., Matos, H. A., Barbosa-Póvoa, A. P. F. D., Fialho, J., Pinheiro, A. S. (2006), Pipeline Scheduling and Inventory Management of a Multiproduct Distribution Oil System, Ind. Eng. Chem. Res., 45, 7841-7855;

RElvas, S., Matos, H. A., Barbosa-Póvoa, A. P. F. D., Fialho, J. (2007), Reactive Scheduling Framework for a Multiproduct Pipeline with Inventory Management, Ind. Eng. Chem. Res., 46, 5659-5676;

RELVAS, S. (2008), Optimal Pipeline Scheduling and Inventory Management of a Multiproduct Oil Distribution Centre, PhD Thesis, Instituto Superior Técnico, Technical University of Lisbon;

RElvaS, S., Barbosa-Póvoa, A. P. F. D., Matos, H. A. (2009), Heuristic batch sequencing on a multiproduct oil distribution system, Comput. Chem. Eng., 33, 712-730;

RElvAS, S., Boschetto Magatão, S.N., Barbosa-Póvoa, A.P.F.D., Neves Jr., F. (2013), Integrated Distribution Scheduling and Inventory Management of an Oil Products Distribution System, Omega, 41 (6), 955-968;

SASIKUMAR, M., Prakash, P.R., Patil, S.M., Ramani, S. (1007) PIPES: A heuristic search model for pipeline schedule generation, Knowledge-Based Systems, 10, 169-175;

SHAH, N. (1996) Mathematical programming techniques for crude oil scheduling, Comput. \& Chem. Eng., 20, S1227-S1232;

SHAH, N.K; Li, Z.; Ierapetritou, M.G. (2011), Petroleum Refining Operations: Key Issues, Advances, and Opportunities, Ind. Eng. Chem. Res., 50 (3), 1161-1170;

TRENCH, Ch. J. (2001), How pipelines make the oil market work their networks, operation, and regulation; Allegro Energy Group, Association of Oil Pipe Lines: New York, 1-20. 